\title{
Measurements in the annular shear layer of high subsonic and under-expanded round jets
}

\author{
Tong Feng ${ }^{1,2} \cdot$ James J. McGuirk ${ }^{1}$
}

Received: 25 June 2015 / Revised: 24 October 2015 / Accepted: 19 November 2015 / Published online: 15 December 2015

(C) The Author(s) 2015. This article is published with open access at Springerlink.com

\begin{abstract}
An experimental study has been undertaken to document compressibility effects in the annular shear layers of axisymmetric jets. Comparison is made of the measured flow development with the well-documented influence of compressibility in planar mixing layers. High Reynolds number $\left(\sim 10^{6}\right)$ and high Mach number jets issuing from a convergent nozzle at nozzle pressure ratios (NPRs) from 1.28 to 3.0 were measured using laser Doppler anemometry instrumentation. Detailed radial profile data are reported, particularly within the potential core region, for mean velocity, turbulence rms, and turbulence shear stress. For supercritical NPRs the presence of the pressure waves in the inviscid shock cell region as the jet expanded back to ambient pressure was found to exert a noticeable effect on shear layer location, causing this to shift radially outwards at high supercritical NPR conditions. After a boundary layer to free shear layer transition zone, the turbulence development displayed a short region of similarity before adjustment to near-field merged jet behaviour. Peak turbulence rms reduction due to compressibility was similar to that observed in planar layers with radial rms suppression much stronger than axial. Comparison of the compressibility-modified annular shear layer growth rate with planar shear layer data on the basis of the convective Mach number $\left(M_{\mathrm{C}}\right)$ showed notable differences; in the annular shear layer, compressibility effects began at lower $M_{\mathrm{C}}$ and
\end{abstract}

James J. McGuirk

j.j.mcguirk@1boro.ac.uk

1 Department of Aeronautical and Automotive Engineering, Loughborough University, Loughborough, Leicestershire LE11 3TU, UK

2 Present Address: School of Mechanical, Aerospace and Civil Engineering, University of Manchester, Manchester M13 9PL, UK displayed a stronger reduction in growth. For high Mach number aerospace propulsion applications involving round jets, the current measurements represent a new data set for the calibration/validation of compressibility-affected turbulence models.

\section{Introduction and background}

The primary engineering application motivating the current work is the increased interest over the last 10-15 years in novel methods for control of spreading rate and enhanced mixing of aeroengine exhaust nozzle jet plumes. Recent attention has focussed on various techniques to manipulate the jet/ambient shear layer development downstream of nozzle exit. For civil aerospace applications, where the design nozzle pressure ratio $(\mathrm{NPR}=$ jet total pressure/ambient static pressure $)$ is typically subcritical and jet Mach number high subsonic, the design target is jet noise reduction; nozzle trailing edge geometry modifications (chevrons or serrations) have been explored to achieve this, see Saiyed et al. (2000). Recent interest in higher cruise performance has extended the range of NPR to supercritical values (Long 2005), introducing the possibility of improperly expanded (overor under-expanded) jets, supersonic Mach numbers and additional shock cell noise. For military aerospace applications, supercritical and improperly expanded jet plumes are common, with the design objective for shear layer manipulation now being enhanced mixing to achieve low observability (infrared signal signature reduction), leading to more aggressive manipulation devices such as tabs protruding into the exhaust stream (Reeder and Samimy 1997; Behrouzi and McGuirk 2009; Feng and McGuirk 2006). 
Underpinning these engineering applications is a large body of fundamental work on the growth rate of turbulent shear layers under conditions of high Reynolds and Mach numbers. Clearly there is a need to understand the characteristics of the baseline jet/ambient shear layer under practically occurring conditions if means for manipulating its behaviour are to be identified effectively. The importance of high Mach number shear layers was signalled by its being selected as a test case for turbulence modelling at one of the first international conferences on this topic in the 1970s (Birch and Eggers 1972). Most of the fundamental research has to date focussed on planar shear layers, with the classical experimental data of Papamoschou and Roshko (1988) documenting the significant reduction in shear layer growth rate due to compressibility effects. This reduction was correlated best against the convective Mach number-the Mach number in a frame of reference moving with the speed $\left(U_{\mathrm{C}}\right)$ of the dominant instability waves (or any other disturbances, e.g. turbulent structures) in the shear layer. The convective Mach numbers of each stream in a two-stream turbulent shear layer are defined via:

$M_{C_{1}}=\frac{U_{1}-U_{c}}{a_{1}} M_{C_{2}}=\frac{U_{c}-U_{2}}{a_{2}}$

For mixing where both streams are pressure-matched and have the same specific heat ratio, the isentropic model suggested by Papamoschou and Roshko (1988) leads to a speed-of-sound weighted average for $U_{\mathrm{C}}$ :

$M_{C_{1}}=M_{C_{2}}=M_{C}=\frac{U_{1}-U_{2}}{a_{1}+a_{2}} \mathrm{U}_{C}=\frac{a_{2} U_{1}+a_{1} U_{2}}{a_{1}+a_{2}}$

$U$ and $a$ are the flow speed and speed of sound, respectively, and subscripts 1 and 2 indicate the faster/slower streams. More recent work by Slessor et al. (2000) has argued for an alternative compressibility parameter $\left(\Pi_{\mathrm{C}}\right)$, which collapses the experimental data better. $\Pi_{\mathrm{C}}$ is based on an expression derived from considerations of the ratio of kinetic energy to thermal energy (enthalpy). However, this alternative view is only significantly different from the $M_{\mathrm{C}}$ characterisation at extreme density ratios between the two streams. Since in the air/air flows of prime consideration here the density ratio only covers values where $\Pi_{\mathrm{C}}$ and $M_{\mathrm{C}}$ are similar, the $M_{\mathrm{C}}$ parameter is retained in the present work.

The early pneumatic probe-based measurements for planar shear layers have been extended using a range of alternative measuring techniques. Hot-wires were used by Barre et al. (1994) and Schlieren/planar laser-induced fluorescence visualisation by Rossmann et al. (2002). The first study reported measurements on mean velocity and on axial normal stress statistics at low $M_{\mathrm{C}}(\sim 0.5$ - at which compressibility-reduced growth rate is just beginning), and the second study added data to the growth rate reduction correlation and extended this to an $M_{\mathrm{C}}$ of 2.25 . It was also suggested that for $M_{\mathrm{C}}>1.0$ the isentropic model for $U_{\mathrm{C}}$ described above was inappropriate and in fact at high $M_{\mathrm{C}}$ turbulent eddies in the fast/slow streams could be convected at fast and slow speeds, respectively. This had first been noted by Lessen et al. (1966) (see also Day et al. 1998) using linear instability analysis of laminar shear layers at high supersonic conditions, showing that at high $M_{\mathrm{C}}$ (>2), as well as the standard instability convecting at $U_{\mathrm{C}}$ (the 'central mode'), additional instability modes travelling at speeds associated with the fast/slow streams, respectively ('outer' modes), could be identified.

Data on turbulence statistics were only forthcoming when non-intrusive laser-based instrumentation was applied. Elliot and Samimy (1990), Goebel and Dutton (1991) used two-component laser Doppler anemometry (LDA) to provide pointwise measurements of mean velocity and Reynolds stress for $M_{\mathrm{C}}$ up to 0.99 and documented the approach to self-similarity of both mean velocity and turbulence statistics in compressible mixing layers. Selfsimilar peak values of streamwise and lateral turbulence intensities as well as Reynolds shear stress all decreased approximately linearly with $M_{\mathrm{C}}$ over the range studied. Attenuation was stronger for lateral intensity and shear stress compared to the streamwise component, although there was some disagreement in the two studies on the streamwise intensity behaviour: Goebel and Dutton (1991) indicated only a very mild reduction, whereas Elliot and Samimy (1990) observed a much stronger decrease. Compressibility effects on turbulence statistics have also been studied using particle image velocimetry (PIV) measurements. Olsen and Dutton (2003) reported at one value of $M_{\mathrm{C}}$, but this was too low $\left(M_{\mathrm{C}}=0.38\right)$ to contribute much of interest. The study of Urban and Mungal (2001), however, covered a range of $M_{\mathrm{C}}(0.25,0.63$ and 0.75$)$ and provided support for the stronger damping of lateral compared to streamwise turbulence intensity. The streamwise rms (nondimensionalised using the change in mean velocity across the mixing layer) decreased by only $9 \%$ as $M_{\mathrm{C}}$ increased from 0.25 to 0.75 , whereas both lateral rms and turbulent shear stress decreased by over $30 \%$; the linear decrease with $M_{\mathrm{C}}$ reported earlier from LDA was also confirmed. The largest discrepancy between the various LDA studies was for the effect of $M_{\mathrm{C}}$ on axial rms, some authors arguing for no effect and others for a weaker effect compared to the lateral rms.

This basic experiment has been repeated by many authors. A recent re-examination by Barone et al. (2006) of 11 sets of experimental data leads to a new recommendation [compared to the so-called Langley curve produced by Birch and Eggers (1972)] for the collapse of the planar mixing layer spreading rate. This paper also reviewed the 
performance of two-equation RANS turbulence models in predicting the growth rate reduction and found that, after including compressibility corrections, errors larger than $10 \%$ over the $M_{\mathrm{C}}$ range $0-1.5$ were still present; they also commented that these compressibility corrections were 'grounded in incorrect physical assumptions'.

The practical importance, particularly for aerospace applications, of compressible shear layers has encouraged CFD studies adopting all levels of turbulence closure for this problem [including no model, i.e. direct numerical simulation (DNS)], and it has become a standard test case for validation of CFD predictions of compressible flows. As noted above, the first proposals for 'compressibility corrections' to enable prediction of an $M_{\mathrm{C}}$ reduced growth rate were within the framework of RANS statistical turbulence models and involved introduction of an additional term in the turbulence dissipation rate equation, based on the concept of dilatational dissipation (Zeman 1990; Sarkar et al. 1991; Sarkar and Lakshmanan 1991; El Baz and Launder 1993). Similarly, Lejeune and Kourta (1997) suggested introduction of an additional modelled term for pressure-dilatation interactions in the transport equation for turbulence energy. However, although models including such terms were calibrated to reproduce growth rate reduction with $M_{\mathrm{C}}$, DNS predictions (for a temporally growing shear layer-self-similar region only) by Vreman et al. (1996) showed that direct dilatational effects on dissipation and pressure terms were insignificant. The alternative they proposed was that growth rate reduction was caused by reduced pressure fluctuations as $M_{\mathrm{C}}$ increased. Modifications to the pressure-strain term were required to capture the spreading rate reduction effect physically correctly. Smaller pressure-strain effects lead to reduced transfer of energy from the streamwise to the lateral component and thus also explain the observed stronger reduction in lateral rms. This interpretation was confirmed in the later (again a temporal shear layer development) DNS study of Pantano and Sarkar (2002). The latest DNS analysis by Zhou et al. (2012) was for a spatially developing shear layer in order to capture the development region of the shear layer downstream of the initial splitter plate as well as the selfsimilar region. Considering $M_{\mathrm{C}}=0.7$ only, the results were consistent with other DNS studies, although the Reynolds number was so low that no $-5 / 3$ region in the energy spectra were observed, and the values predicted for peak turbulence intensities were perhaps not in such good agreement with measurements for this reason.

Motivated by the information provided by these DNS studies, efforts to develop RANS compressibility models for the pressure-strain term have been explored by Batten et al. (1999), Fujiwara et al. (2000), and Gomez and Girimaji (2013). The last of these is the most comprehensive study, involving the use of rapid distortion theory as well as DNS results to develop a compressible pressure-strain model. Model coefficients were calibrated against compressible homogeneous shear flow data, with coefficients sensitised to compressibility using the gradient Mach number $M_{\mathrm{G}}$ (the ratio of shear and acoustic timescales, i.e. $S l / a$ - where $S$ is the strain rate magnitude and $l$ is a characteristic flow length scale); agreement with the measurements of Goebel and Dutton (1991) was very good for both streamwise and lateral rms levels as well as the Reynolds shear stress. Finally, reflecting the trend in the last decade or more for applied (high Reynolds number) CFD to prefer large Eddy simulation (LES) rather than advanced second-moment closure RANS turbulence models, two applications of LES to compressible planar shear layers have appeared: Le Ribault (2005) and Fu and Li (2006). Both of these have reported good agreement with growth rate reduction with $M_{\mathrm{C}}$, with the influence of subgrid scale (SGS) model only having a small effect. Prediction of peak streamwise/lateral rms intensity levels as $M_{\mathrm{C}}$ varied was also reported by Le Ribault (2005), but agreement with measurements was here not as good. Both papers processed their simulations to produce assessment of various terms in the time-averaged turbulence energy equation; a large decrease in production with $M_{\mathrm{C}}$ was observed as in the DNS results of Pantano and Sarkar (2002) as well as a strong reduction in pressure-strain term components for the streamwise and Reynolds stress, demonstrating that the main compressibility effect could be directly captured in LES without any SGS model modifications.

One aspect, which is undoubtedly important in the engineering context of round jet plume development, has, however, received rather sparse attention. This is the study of annular or axisymmetric rather than planar shear layers. Whilst the initial region (perhaps the first three jet diameters) of a round jet/ambient shear layer will almost certainly behave like a planar shear layer, this is less obvious for the shear layer development up to the end of the potential core ( $\sim 5$ to 6 jet diameters), where the ratio of shear layer thickness to jet radius is no longer small. In fact, only two experimental studies which have explicitly set out to examine compressibility effects in annular/axisymmetric shear layers have appeared in the last 15 years-Bellaud et al. (1999) and Thurow et al. (2003, 2008)—where measurements were taken within the potential core region of a round jet. Unfortunately, both of these studies had their limitations. In Bellaud et al. (1999), the fully expanded supersonic $(M=2.5)$ jet was surrounded by co-flowing stream at $M=0.2$ (thus $M_{\mathrm{C}}=0.9$ ), so both compressibility and co-flow would affect the observed spreading rate. Two-component LDA data taken in the annular shear layer led the authors to comment that the growth rate was 'close to' a planar shear layer at the same $M_{\mathrm{c}}$, but no specific data on this were presented. The initial conclusion 
was that axisymmetric and planar shear layer development was similar, but this was supported by little explicit evidence and no variation with $M_{\mathrm{C}}$ was explored. Thurow et al. (2003) also used properly expanded supersonic jets at $M_{\mathrm{J}}=1.3$ and 2.0 to examine axisymmetric jet shear layers at $M_{\mathrm{C}}: 0.59$ and 0.87 . However, to facilitate application of the experimental technique used (which tracked individual turbulent structures identified within the shear layer), measurement locations were chosen that specifically avoided 'interaction between structures on both sides of the centreline', and so the data obtained were effectively restricted to axisymmetric layers with large radius ratios. Visualisation of the flow structures was achieved by laser-sheet imaging of small water droplets formed as the warm humid ambient air was entrained into the cold high-speed jet. Timeco-ordinated sequences of flow visualisation images in the axial-radial plane were used to deduce space-time correlations in which flow structures were tracked, with the peaks in these correlation curves used to calculate the eddy convection velocity $U_{\mathrm{C}}$. In Thurow et al. (2003), it was concluded that differences between axisymmetric and planar shear layers could be seen in that the 'fast' and 'slow' modes referred to above were identified. Unfortunately, this was later retracted (Thurow et al. 2008) as being more connected with details of the seeding and image processing method used. Thus, surprisingly given their high practical relevance, there seems to be no specific and comprehensive data comparing annular/axisymmetric shear layers bordering round jets with their planar equivalent.

Indirectly, conclusions on annular shear layer growth rate may be inferred from data on the potential core length $\left(L_{\mathrm{PC}}\right)$ of compressible round jets. Witze (1974) produced an empirical correlation showing how $L_{\mathrm{PC}}$ increased with jet Mach number $\left(M_{\mathrm{J}}\right)$, consistent with the $M_{\mathrm{C}}$ influence measured in planar shear layers, although at this early date no specific link with $M_{\mathrm{C}}$ was made. Lau et al. (1979) and Lau (1981) also observed that high $M_{\mathrm{J}}$ increased $L_{\mathrm{PC}}$, but no attempt was made to extract annular shear layer growth rate or compare with planar shear layer data. A considerable body of detailed flow and turbulence measurements on the near field of high subsonic round jets (and also hot jots) has been carried out at NASA Glenn Research Center (Brown and Bridges 2006; Wernet 2007; Bridges and Wernet 2003, 2010). The $L_{\mathrm{PC}}$ correlation of Witze was revisited in this work and found to collapse the centreline mean velocity development of jets for NPRs from 1.2 to 1.89 well (although did not do so as well for turbulence kinetic energy), but no high $M_{\mathrm{C}}$ values were covered by this data. Work by Zaman (1998) on the asymptotic (self-similar) spreading rate for compressible jets has indicated the difficulty of deducing annular shear layer behaviour from $L_{\mathrm{PC}}$ data, since variations in static pressure and density at nozzle exit as NPR varies also influence $L_{\mathrm{PC}}$ at high Mach number.

In terms of CFD studies on compressible annular shear layers or axisymmetric jets, only the DNS study of an annular shear layer by Freund et al. (2000) and the second-moment closure RANS jet flow predictions of Ess and Leschziner (2005) have addressed such flows explicitly. The DNS analysis considered a temporally developing shear layer with streamwise periodic conditions; however, even at the final time of analysis, the radius only varied by $\pm 10 \%$ over the shear layer, so it is perhaps not surprising that the simulation showed annular and planar shear layers were very similar. The RANS study explored various pressure-strain model compressibility corrections [those of El Baz and Launder (1993) and Pantano and Sarkar (2002)] applied to under-expanded jets. The compressibility corrections had either a marginal influence, or even worsened the agreement with experimental data, so further work to guide model testing is clearly needed.

Finally, in the context of the engineering application of interest here, it should also be noted that all of the experimental data mentioned above were taken under conditions of full expansion of the jet (con-di nozzles operated at design NPR were used to expand to shock-free supersonic jets for NPRs $>1.89$ ). Only the measurements of Saddington et al. (2004) and Zeman (1998) have considered underand over-expanded jets, but no measurements were taken of shear layer development, so it is not clear the extent to which the shock cells in the jet core under improperly expanded conditions affected the shear layer behaviour compared to planar and properly expanded flows.

The review of previous studies presented above has indicated that there is a clear gap in knowledge and available data of relevance to the question of similarity (or not) of compressibility effects on annular as opposed to planar shear layers. The continuing interest in development of compressibility-corrected turbulence models for CFD prediction of aerospace propulsion-related flows means it is important to confirm that the existing 'benchmark' test case for validating new model developments [the $M_{\mathrm{C}}$ growth rate reduction curve of Barone et al. (2006)] is appropriate for annular shear layers bordering round jets. It was thus the main objective of the present work to carry out an experimental investigation of such high Mach number annular shear layers. A range of jet NPRs covering values of practical interest were selected including moderately underexpanded cases; shear layer development over the whole potential core length and the initial region of jet merging has been considered. Care was taken to ensure that the data were gathered under carefully controlled conditions that minimised nozzle exit boundary layer effects. Detailed mean velocity and turbulence statistics were gathered using 
Fig. 1 High-Pressure Nozzle Test Facility, a photograph, b layout (a)

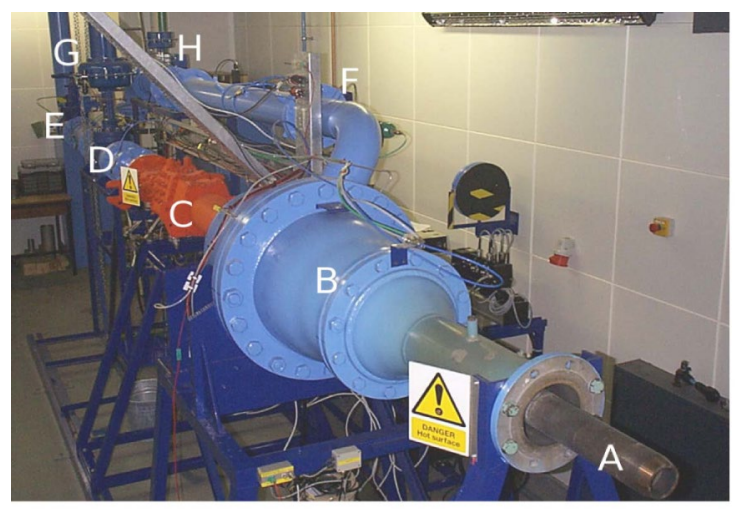

(b)

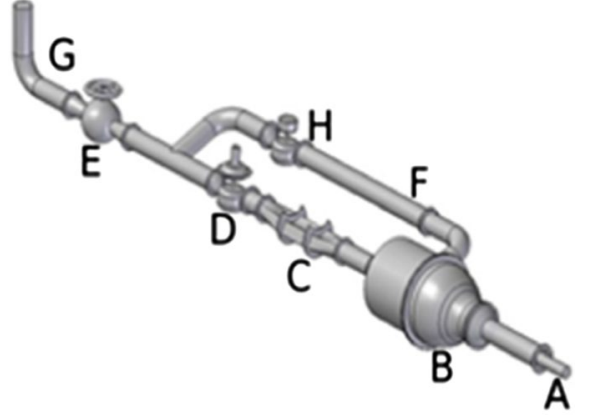

\begin{tabular}{||ll||}
\hline \hline A & Primary nozzle delivery pipe \\
\hline B & $\begin{array}{l}\text { Secondary nozzle plenum and } \\
\text { contraction }\end{array}$ \\
\hline C & Combustion chamber \\
\hline D & Prim. nozzle control valve \\
\hline E & Isolating globe valve \\
\hline F & Sec. nozzle delivery pipe \\
\hline G & Rig air supply pipe \\
\hline H & Sec. nozzle control valve \\
\hline
\end{tabular}

LDA instrumentation. The data were processed to allow direct quantitative comparison between planar and annular shear layer growth rate suppression for the $M_{\mathrm{C}}$ range relevant to the current engineering applications (approximately $0.2-1.0)$. The primary intention of the work reported here was to establish an experimental data base that would: (1) place particular focus on annular shear layer behaviour over the whole range of radius ratio experience in the engineering applications of interest, (2) extend the range of flows studied to include the regime of under-expanded NPR, (3) form a benchmark CFD validation test case.

\section{Experimental details, instrumentation and preliminary measurements}

Experiments were carried out using the Loughborough University High-Pressure Nozzle Test Facility (HPNTF) for supersonic nozzle flow studies. A detailed description of the facility has been provided by Feng and McGuirk (2007). A 0.15 -m diameter air supply pipeline $(G)$ delivers high-pressure (HP) air (15 bars abs) into the HPNTF test cell (Fig. 1). The HP air is dried in a desiccant drier to a dew point of $-40{ }^{\circ} \mathrm{C}$ and stored in air receiver tanks with a total volume of $110 \mathrm{~m}^{3}$. The tanks serve as pulsation dampers as well as an air reservoir when the system is operated in 'blowdown' mode if the required air mass flow rate exceeds the maximum continuous supply rate $(1 \mathrm{~kg} / \mathrm{s})$. The supply line contains a control valve for coarse regulation of the pressure to $\sim 5$ bars. Within the test cell, a globe valve $(E)$ isolates the rig from the supply pipe if needed. The flow is split into two streams: one to supply a primary nozzle $(A)$ and the other to supply a larger-diameter co-axial secondary nozzle (not used in the present study) via a branched delivery pipe $(F)$; the primary stream contains a plenum and contraction $(B)$. All data reported here are for primary nozzle flow alone. Mass flow and pressure control are carried out using fine control valves ( $D$ for primary flow, $H$ for secondary). These are computer-controlled pneumatic valves, which are automatically adjusted to hold the NPR to a constant value (typically 1.3-4.0) to an accuracy of $\pm 1 \%$; a typical blowdown time is $\sim 30 \mathrm{~min}$. The facility can also produce heated jets using a combustor $(C)$ located downstream of the primary control valve. The data reported here are for unheated flow, i.e. jet fluid total temperature equal to ambient air temperature $(\sim 278 \mathrm{~K})$. The horizontal jet from the test nozzle (mounted on the end of pipe $A$ ) is available for detailed plume characterisation in a test section length of $\sim 1.5 \mathrm{~m}$ before entering a detuner for noise attenuation and exhaust.

For the present tests, a conical convergent nozzle of exit diameter $D_{\mathrm{J}}=48 \mathrm{~mm}$ was used; this was provided with a short $(\sim 30 \mathrm{~mm})$ parallel extension to minimise any vena contracta effects; the nozzle size was chosen large enough to produce jet Reynolds numbers representative of practical engineering applications (of order $\left.R e_{\mathrm{J}}=\rho_{\mathrm{J}} U_{\mathrm{J}} D_{\mathrm{J}} / \mu_{\mathrm{J}}=10^{6}\right)$. The nozzle dimensions are 

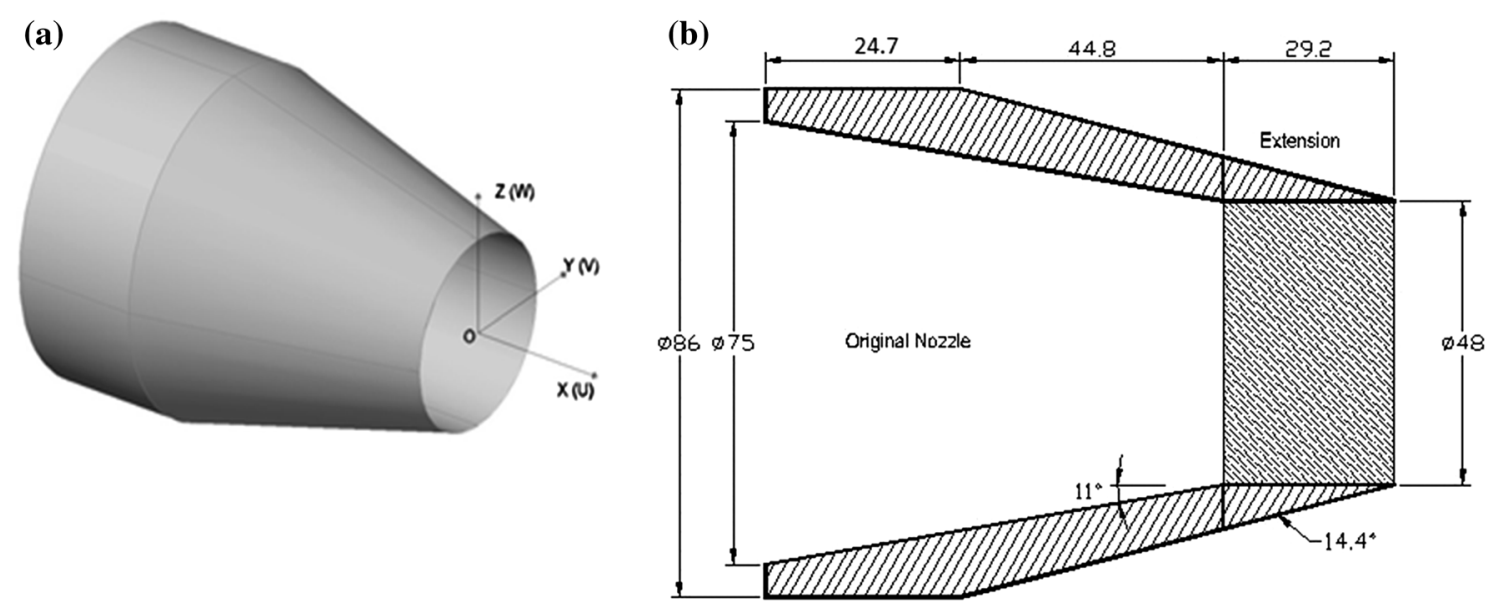

Fig. 2 a Axisymmetric nozzle geometry, b nozzle dimensions (mm)

shown in Fig. 2. The co-ordinate system used to present the data has the $x$-axis in the jet direction, the $y$-axis horizontal, and the $z$-axis vertical. Initial measurements of axial velocity were taken in both a vertical $x-z$ plane and a horizontal $y-z$ plane passing through the nozzle exit centreline; these indicated excellent axisymmetry, so only $x-z$ data are presented here ( $U$ and $W$ velocity components were captured with the two-component LDA system described below).

It has been noted in the work of Lepicovsky (1990) that the state of a strongly convergent nozzle exit boundary layer can change from turbulent to transitional to laminar as jet NPR is increased. This is due to the well-known effect of a strong favourable pressure gradient creating relaminarisation in the wall boundary layer profile, but can make quantitative assessment of jet spreading effects with NPR changes difficult to identify particularly if the focus of attention is on the near-field shear layer behaviour. The work of Trumper (2006), using a nozzle of the same design as shown in Fig. 2, has shown that a short parallel nozzle extension attached to the convergence provides opportunity for the wall boundary layer, which has experienced strong acceleration (and hence possible relaminarisation) as it passes through the nozzle, to relax back towards a fully turbulent state before reaching nozzle exit. Thus, any vena contracta effect is removed and the flow exits the nozzle axially with a turbulent boundary layer state. Figure 3 shows measurements of the wall boundary layer at nozzle inlet carried out with a flattened boundary layer Pitot probe with a sensing height of $0.11 \mathrm{~mm}$, and also at nozzle exit with an LDA system (the exit profiles were measured $0.05 \mathrm{~mm}$ outside the nozzle). Figure $3 \mathrm{a}$ shows that the nozzle inlet boundary layer is clearly turbulent since, when plotted in conventional wall co-ordinates $\left(u^{+}\right.$vs $\left.y^{+}\right)$, it fits the standard log-law line well. Due to the long approach length of the supply pipe, the inlet boundary layer thickness $(\delta)$ was $21.8 \mathrm{~mm}(\sim 60 \%$ of the inlet pipe radius $)$ at NPR $=1.89$, reducing to $\delta=19.4 \mathrm{~mm}(\sim 50 \%$ of radius) at NPR $=2.40$. Figure $3 \mathrm{~b}$ shows the change in boundary layer characteristics between inlet and outlet (plotted in conventional non-dimensional form using the inlet displacement thickness $\left(\delta_{i}^{*}\right)$ and edge velocity $\left(U_{\delta}\right)$ as reference scales). Note that these results are for a nozzle without an added parallel extension. The effects on the profile shape caused by flow acceleration are immediately apparent; the boundary layer thickness at nozzle exit was only $0.38 \mathrm{~mm}$ at NPR $=1.89$, a reduction of approximately a factor of 60 (relative to the inlet boundary layer thickness of $21.8 \mathrm{~mm}$ ) in an axial length of little more than 1.5 nozzle exit diameters. There is no change in the exit profile shape with NPR over the range studied; the near wall gradient is much shallower than at nozzle inlet, leading to the exit profile crossing over the inlet profile at approximately $y / \delta^{*}=1.0$; the profile shape is certainly more laminar-like compared to the fully turbulent inlet profile. Relaminarisation has clearly occurred, and this was confirmed on evaluation of the boundary layer shape factor (see Table 1 below). LDA-measured nozzle exit profiles are shown again in Fig. 3c, including both with (LU48P) and without (LU48) an exit parallel extension. The profile with added extension shows clear signs of recovery towards a fuller turbulent shape. This is further examined in Fig. 3d, which presents the same exit profiles in semi-logarithmic Clauser plot form and at two NPRs; the exit profiles with extension have not fully recovered to an equilibrium fully turbulent state but are much closer to this than the profile without extension. Table 1 shows the effect of adding the short extension on the nozzle on overall exit boundary layer parameters. From the same fully turbulent boundary layer at inlet, the conical nozzle without extension shows an exit boundary layer with a laminar shape factor and a very low momentum thickness Reynolds number. By adding a short parallel extension, the nozzle exit boundary layer has 

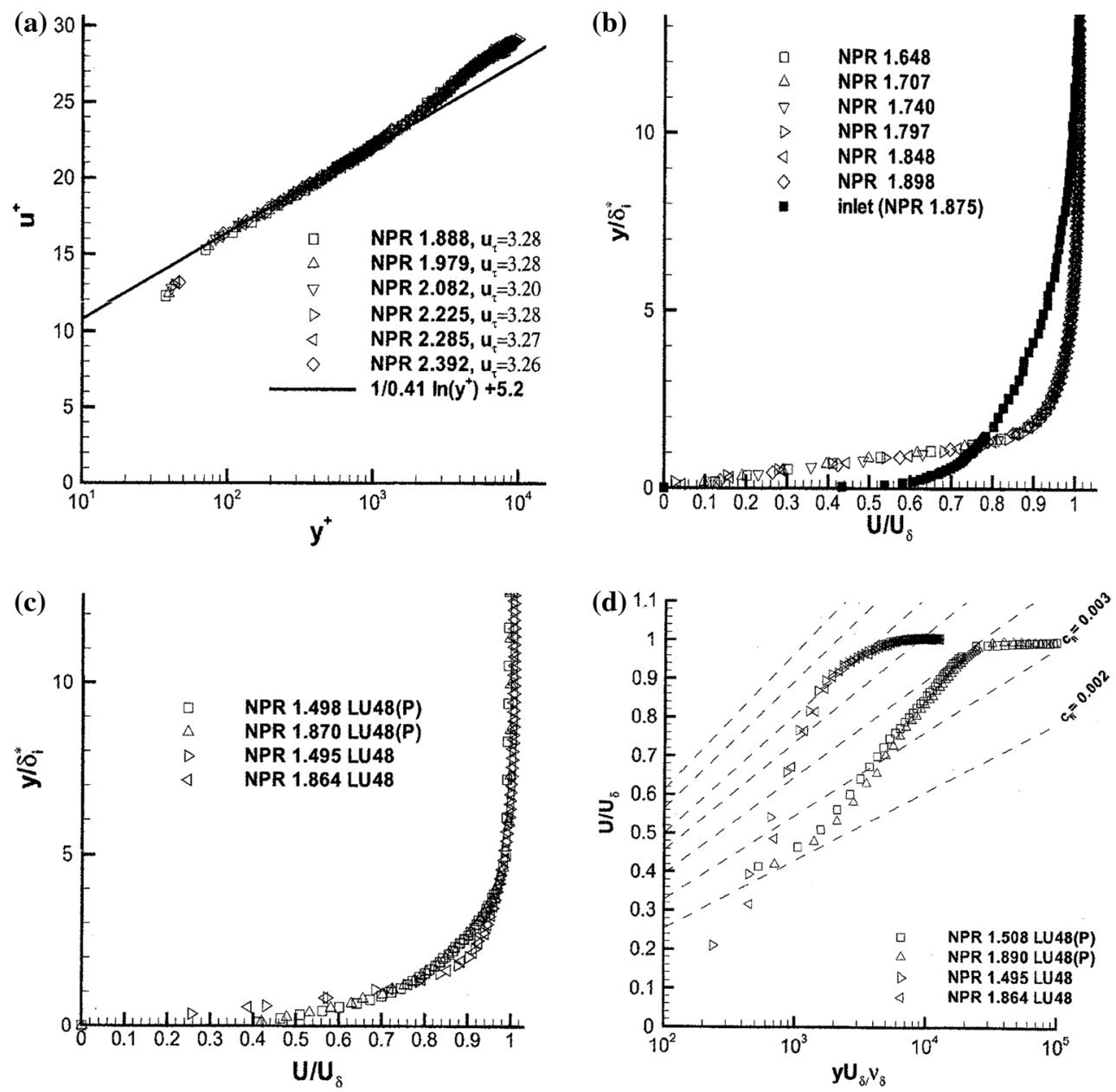

Fig. 3 Nozzle inlet and exit boundary layer measurements (Trumper (2006). a Inlet boundary layer profile in wall-law co-ordinates, b inlet boundary layer in standard co-ordinate form, $\mathbf{c}$ exit boundary layer

with and without exit parallel extension, $\mathbf{d}$ exit boundary layer in Clauser chart format

Table 1 Nozzle inlet and exit boundary layer parameters for $\mathrm{NPR}=1.88$ (Trumper 2006)

\begin{tabular}{lll}
\hline & $D=48 \mathrm{~mm}$ no extension & $D=48 \mathrm{~mm}$ with extension \\
\hline Nozzle inlet & & \\
Momentum thickness $\theta(\mathrm{mm})$ & 1.5 & 1.5 \\
$R e_{\theta}$ & 15,000 & 15,000 \\
Shape factor $H$ & 1.33 & 1.33 \\
Nozzle exit & & \\
Momentum thickness $\theta(\mathrm{mm})$ & 0.0216 & 0.168 \\
$\operatorname{Re}_{\theta}$ & 525 & 3513 \\
Shape factor $H$ & 2.15 & 1.33 \\
\hline
\end{tabular}

recovered to a momentum thickness eight times larger and a turbulent shape factor. The added extension has therefore been included in all tests reported here so that under all conditions tested the nozzle exit boundary layer was turbulent with a momentum thickness Reynolds number of order 4000 and shape factor $H \sim 1.33$. Accordingly, changes observed in annular shear layer behaviour can be confidently related to nozzle operating condition (NPR) and compressibility effects, rather than caused by nozzle exit boundary layer state change.

Colour Schlieren imaging and LDA measurements have been carried out. The colour Schlieren system used an orange-blue-green (rainbow) slide as a (horizontally orientated) 'knife-edge', orange indicating regions of expansion, 

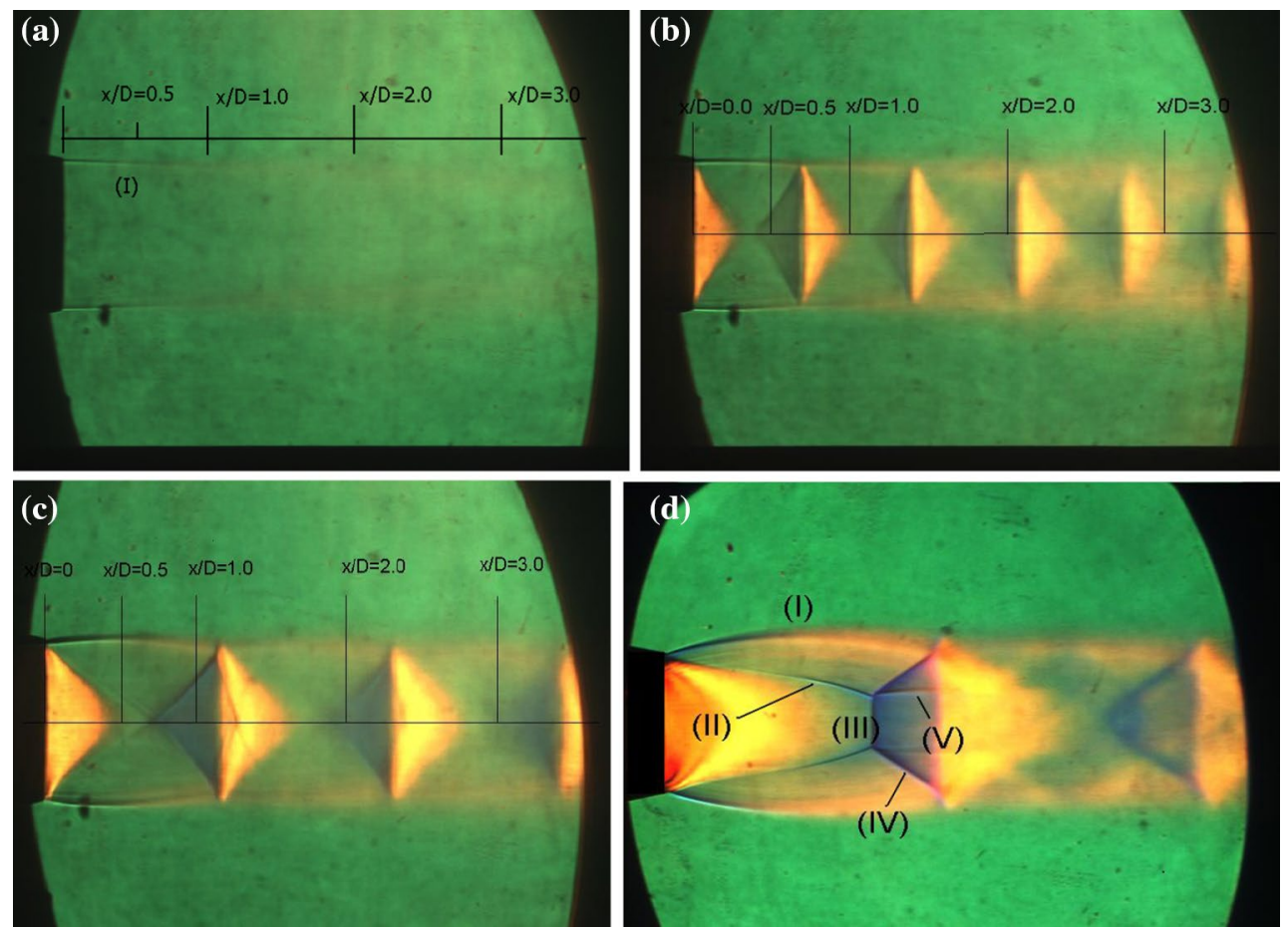

Fig. 4 Schlieren images at various NPR. a NPR $=1.89, \mathbf{b}$ NPR $=2.32, \mathbf{c}$ NPR $=3.0, \mathbf{d}$ NPR $=6.0$

blue indicating compression regions, and green corresponding to undeflected light making up the neutral background. Schlieren pictures were taken of the area just downstream of the nozzle exit (up to around $x / D \sim 4$ ). This system was used to select the range of NPR for detailed testing. Figure 4 shows typical Schlieren images for NPRs ranging from just critical (NPR $=1.89$, nozzle just choked) to highly underexpanded (NPR $=6.0)$. As NPR exceeds the critical value, a train of shock cells appears in the under-expanded jet plume with each of the shock cells containing a pair of expansion and compression regions. The changing character of these shock cells and the appearance and increasing strength of a Mach disc with increasing NPR are shown in Fig. 4.

The characteristic features of under-expanded jets are highlighted in the fourth image: I-the external jet/ambient constant pressure boundary; II-the incident or inception shock, III-the Mach disc (at higher NPR); IV-the conical or reflected shock; V-the internal slip line (at higher NPR). At a moderately under-expanded NPR (2.32), a large number of relatively short and weak shock cells are seen; at highly under-expanded NPRs (>4.0), the jet/ambient boundary becomes highly curved (barrel shaped), the shock cells are much longer, and a Mach disc (normal shock) appears on the jet centreline, with a region of subsonic flow downstream indicated by the presence of an internal slip line best seen at NPR $=6.0$. One of the noticeable features of the first shock cell is that the length of the expansion and compression regions changes

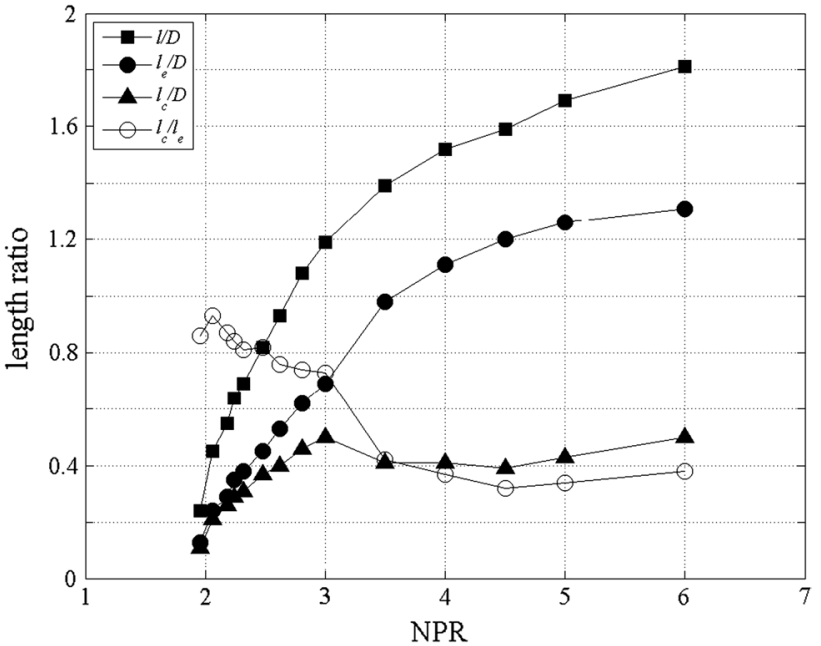

Fig. 5 Dimensions of first shock cell

considerably with NPR. The total length of the first shock cell $(l)$, the length of expansion $\left(l_{\mathrm{e}}\right)$ and compression regions $\left(l_{\mathrm{c}}\right)$ are shown in Fig. 5.

After examination of these images, it was decided to concentrate LDA measurements on the NPR range from 1.28 to 3.0. More highly expanded cases are not of high priority in the engineering applications of most interest here, and the rig blow-down times needed (even at NPR $=3.0$ ) made LDA measurement time-consuming. 
Fig. 6 Frequency spectrum of acoustic noise at NPR 2.5-3.0

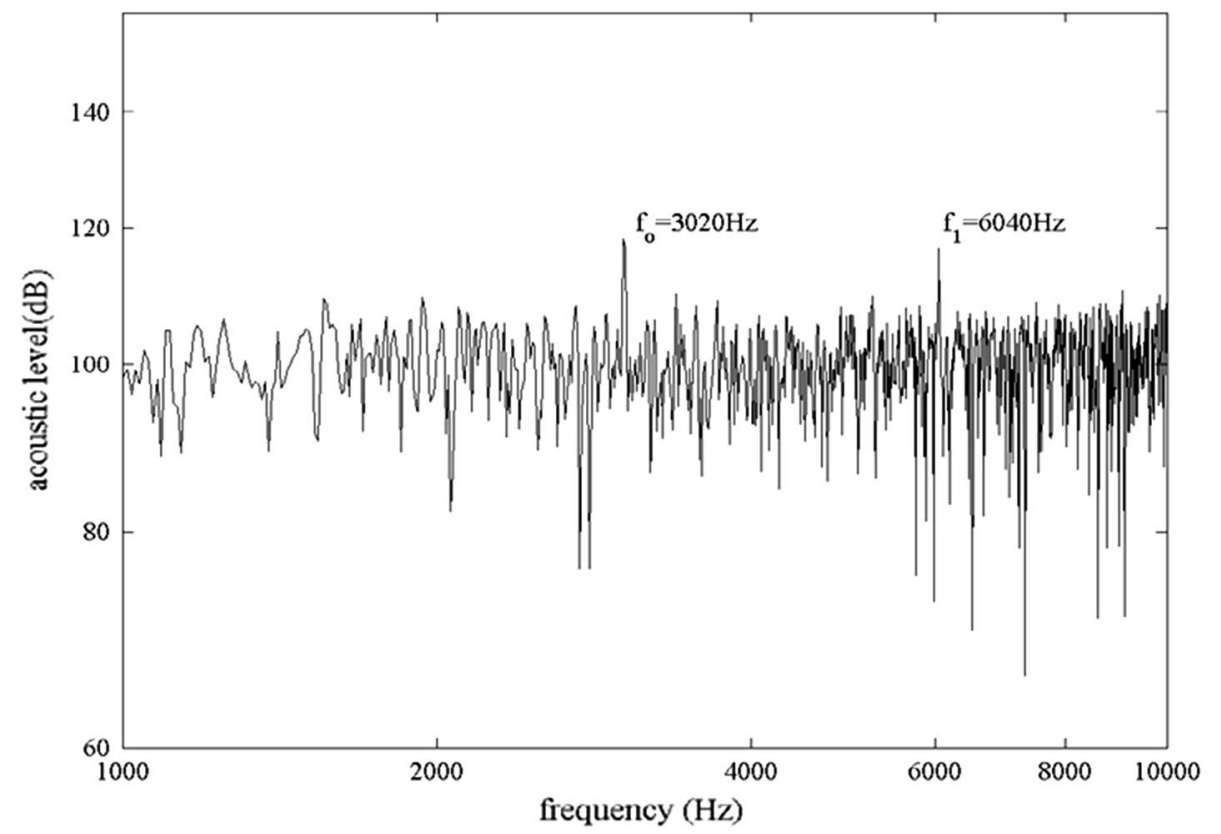

Fig. 7 LDA system and traversing table with conical nozzle

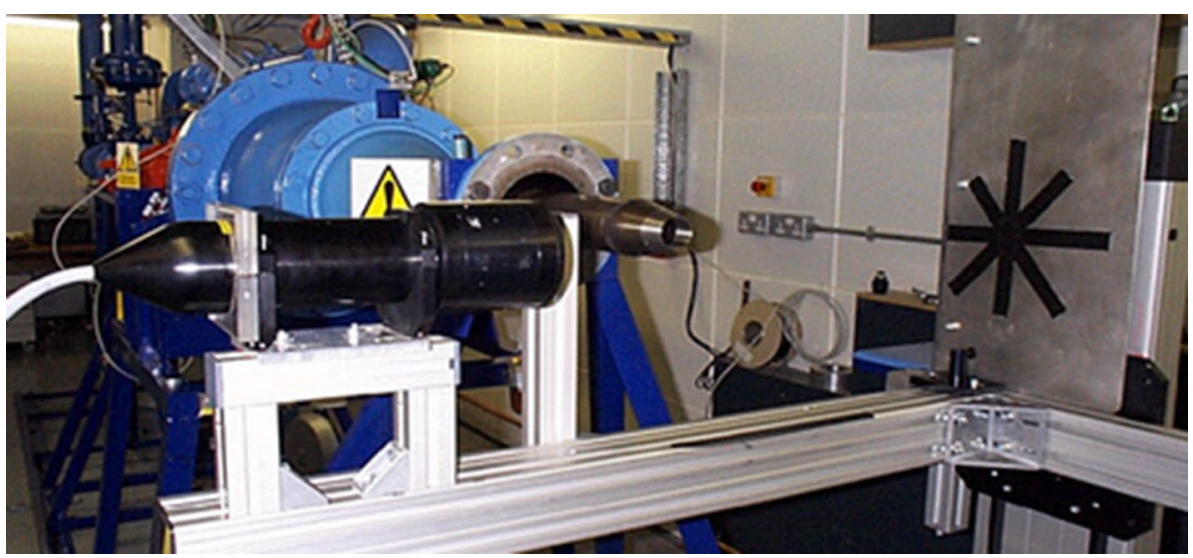

For NPR between $\sim 2.5$ and 3, acoustic measurements in the test cell revealed a screech phenomenon (principle frequency $\sim 3 \mathrm{kHz}$ ), which was not present at lower or higher NPR; the high amplitude tonal noise signals can be clearly seen in the acoustic pressure spectrum shown in Fig. 6 (fundamental and first harmonic). To avoid any screech-induced unsteady flow effects, the NPRs at which turbulence measurements were gathered and analysed were therefore chosen as NPR = 2.32 and 3.0; for NPRs between these two values, it was judged that the screech signal became too strong (the noise amplitude in the test cell increased by more than $5 \mathrm{~dB}$ for NPR $>\sim 2.35$ ).

The LDA instrumentation (Fig. 7) is a two-component (blue/green laser beams) Dantec fibre optic system, made up of a 4-W argon ion laser source, a beam splitter and manipulator and a signal processor (BSA F80) specially designed for high-speed flow measurement. The maximum resolvable frequency was $180 \mathrm{MHz}$, which, with the optical arrangement used, corresponded to a flow velocity of $\sim 800 \mathrm{~m} / \mathrm{s}$. The LDA system was mounted on a 3D traversing table with a positioning accuracy of $0.05 \mathrm{~mm}$; beam expanders were used to reduce the size of the measuring volume as far as possible. The optical parameters of the LDA system are detailed in Table 2.

Seeding was provided either via liquid droplets with an average size of $0.3 \mu \mathrm{m}$ and a density of $920 \mathrm{~kg} / \mathrm{m}^{3}$, or via solid alumina oxide particles with the same average diameter and a density of $3960 \mathrm{~kg} / \mathrm{m}^{3}$ (particle size taken from manufacturer's specifications). Seeding was introduced at a location in the supply pipe $2.5 \mathrm{~m}$ upstream of the nozzle; because the flow was fully turbulent in the supply pipe, this ensured the particles were fully mixed across the whole nozzle diameter. Both these particles will follow the expected turbulence frequencies faithfully. The analysis of Melling 
Table 2 Optical parameters of LDA system

\begin{tabular}{llllllll}
\hline & $L(\mathrm{~mm})$ & $\theta\left(^{\circ}\right)$ & $s(\mu \mathrm{m})$ & $N_{\mathrm{f}}$ & $d_{\mathrm{x}}(\mathrm{mm})$ & $d_{\mathrm{y}}(\mathrm{mm})$ & $d_{\mathrm{z}}(\mathrm{mm})$ \\
\hline Green beam $\left(\lambda_{\mathrm{G}}=514.5 \mathrm{~nm}\right)$ & 310 & 7.01 & 4.15 & 18 & 0.076 & 0.076 & 1.192 \\
Blue beam $\left(\lambda_{\mathrm{B}}=488.0 \mathrm{~nm}\right)$ & 310 & 7.01 & 3.94 & 18 & 0.072 & 0.072 & 1.131 \\
\hline
\end{tabular}

$L$ focal length, $\theta 1 / 2$ beam intersection angle

$s, N_{\mathrm{f}}$ fringe spacing and no., $d_{\mathrm{x}} / d_{\mathrm{y}} / d_{\mathrm{z}}$ LDA measuring volume size
(1997) for the unsteady particle motion induced by a turbulent frequency $f_{\mathrm{T}}$ was used to estimate the tracking error using the estimate of turbulent timescale in a jet as provided by Tinney et al. (2008); this resulted in an estimated tracking error of order $1 \%$ for $f_{\mathrm{T}}=10 \mathrm{kHz}$. Solid seeding particles were, however, preferable in that they provided a high signal-to-noise ratio of scattered light leading to a higher validated data rate. The particle data rate was typically $10 \mathrm{kHz}$ for spectral measurements, with a measurement time of $60 \mathrm{~s}$ using equal temporal spacing mode; for velocity traverse data a rate of $4 \mathrm{kHz}$ in transit time mode for $5 \mathrm{~s}$ was used; a population of $20 \mathrm{k}$ validated readings was thus used to evaluate time-averaged statistics. It is important to note that seeding was added to the jet flow only, and no seeding was provided in the ambient flow entrained by the jet, as adopted for example in the jet flow studies of Bridges and Wernet (2010), or Guitton et al. (2007). This has implications for the accuracy of measurements in the immediate vicinity of the jet/ambient edge. This problem was mitigated partially by the fact that the static temperature of the jet air was reduced significantly below that of the ambient for the NPRs corresponding to the three $M_{\mathrm{C}}$ conditions chosen for measurement (these were $M_{\mathrm{C}}=0.38,0.46$ and 0.56, see below). Condensation of the moisture in the ambient air entrained into the plume then takes place, and these act as naturally formed seeding particles (typical size $50 \mu \mathrm{m}$ ); however, there will still be LDA measurement error in the very low velocity regions $(<10 \mathrm{~m} / \mathrm{s})$. Apart from a short region within the first diameter after nozzle exit, this problem will not influence data taken on the lipline, and the measure of shear layer thickness that is used below (vorticity thickness, Barone et al. 2006) does not require the jet edge to be detected, rather the location of maximum shear, which lies well inboard of this.

The ability of liquid or solid seed particles to follow the rapid spatial velocity changes in the high gradient regions of the shock cells is an important influence on measurement accuracy. This so-called velocity slip error has been examined in the PIV study of Ross et al. (1994), and their approach is followed here. By assuming a Stokes drag law for a sphere and calculating a particle response time $\left(\tau_{\mathrm{P}}=\rho_{\mathrm{P}} d_{\mathrm{P}} / 18 \mu\right)$, the time taken for a seeding particle to respond to a step change in velocity across a shock wave may be calculated. After a time of $2 \tau_{\mathrm{p}}$, the difference between particle and gas flow velocity is $\sim 13 \%$ and this is referred to as the particle relaxation time; a relaxation length may be calculated as the distance moved by the particle in this time. Using this approach, the relevant particle relaxation times and lengths for liquid/solid seeding in the current case are $0.26 / 1.1 \mu \mathrm{s}$ and $0.25 / 1.08 \mathrm{~mm}$, respectively. It would clearly be better to use the liquid droplets, but this is not practical due to the relatively poorer reflective capability of the liquid droplets in the harsh flow environment of supersonic jet flow. To quantify the significance of the velocity slip error, tests using both seeding particles were carried out for NPR $=3.0$ in the jet near field $(x / D=0.5$ and 1.0$)$ where liquid seeding signal-tonoise ratio was still acceptable. Within the first shock cell gradients are steepest and particle lag will introduce largest errors (the problem is less severe downstream); results for the time-averaged profiles of axial velocity and axial turbulence rms at these two locations are shown in Fig. 8. The mean velocity measurements show that at the first measurement station $(x / D=0.5)$ the liquid seeding data are in general at a higher velocity than the solid seeding data. This is as expected since this location is at the end of the first expansion region (see Fig. 4) where the flow accelerates; the liquid particles are expected to accelerate more than the solid. Similarly, the second station $(x / D=1.0)$ lies towards the end of the compression zone (Fig. 4) where the flow has been decelerating, with the liquid particle velocity changing from its value at $x / D=0.5$ by approximately $-110 \mathrm{~m} / \mathrm{s}$ and the solid by only $-95 \mathrm{~m} / \mathrm{s}$. Quantitatively, the difference in the jet centre and in the shear layer region (where the measurement error is of more concern) is $\sim 12 \%$ (centreline) and $\sim 1 \%$ (shear layer) at both $x / D=0.5$ and 1.0. For the measured turbulence level in the shear layer, the difference is $\sim 1.5 \%$ at $x / D=0.5$ and $<1 \%$ at $x / D=1.0$ (the differences are larger in the jet core, but this is not true turbulence but irrotational unsteadiness driving shock cell oscillation (see below) and is of less concern in the present context). The conclusion is that the solid seeding can be used for the shear layer study undertaken here.

Finally, the error caused by particle velocity bias has also been estimated, using the approach of McLaughlin and Tiedermann (1973); assuming that the maximum turbulence intensity near the jet nozzle is $\sim 20 \%$, this error was calculated as $<5 \%$. Whilst this is considered acceptably small, and in their investigation of an annular supersonic mixing layer (using similar seeding and LDA instrumentation), 

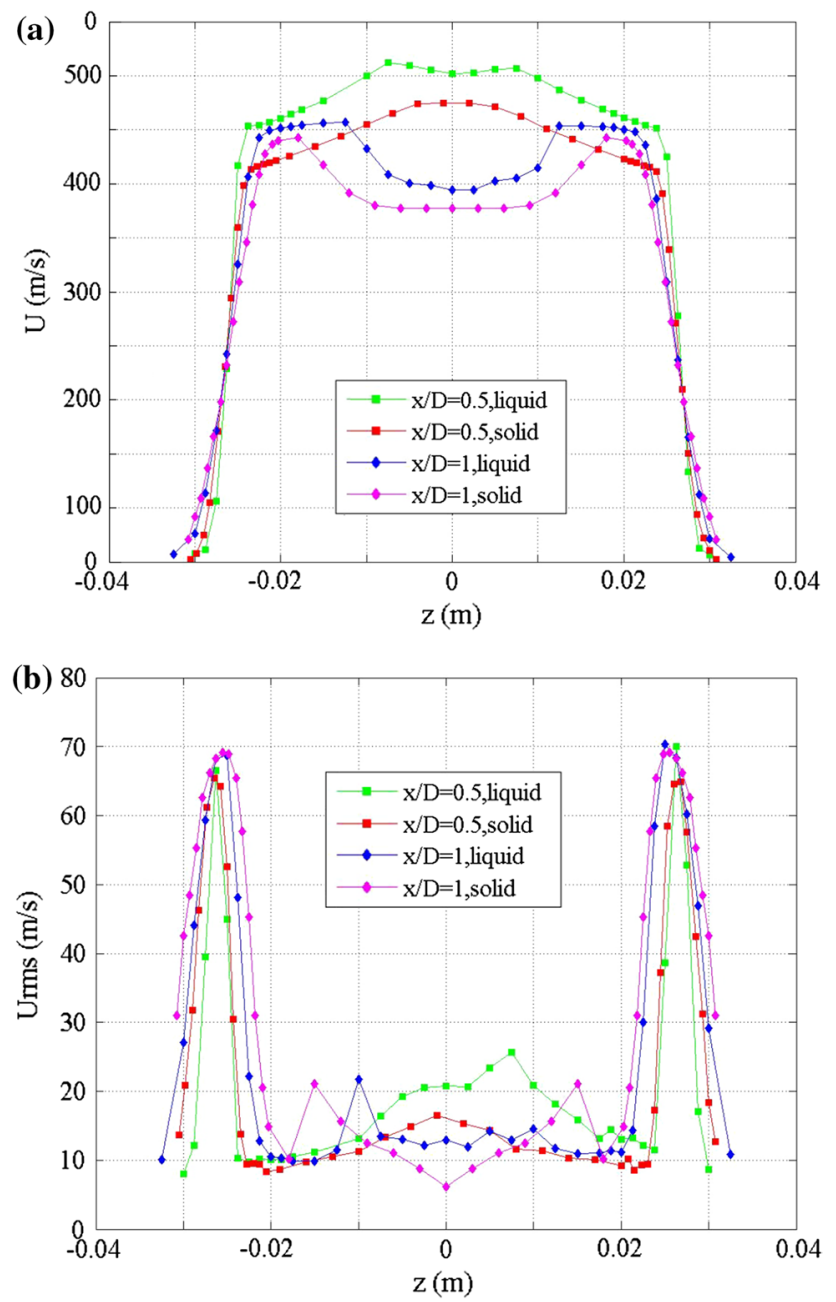

Fig. 8 Seeding particle tests at NPR $=3.0: x / D=0.5$ and 1.0; $\mathbf{a}$ mean axial velocity, b axial $\mathrm{rms}$

Fig. 9 a Transit time and $\mathbf{b}$ arrival time for $500 \mathrm{k}$ samples at $U_{\mathrm{j}}=250 \mathrm{~m} / \mathrm{s}$
Bellaud et al. (1999) found no measurable velocity bias employing either interval-time or transit-time weighting; the present velocity statistics measurements were taken employing transit-time weighting. Typical distributions of transit time and arrival time of the seeding particles are shown in Fig. 9 for 500,000 samples collected with a nozzle jet exit flow velocity of $250 \mathrm{~m} / \mathrm{s}$. The transit time was in the range $0.1-0.3 \mu \mathrm{s}$, whereas the arrival time was in the range $0-0.1 \mathrm{~ms}$. By using the equal temporal spacing mode of sampling offered with the BSA F80 processor, this allowed a sample rate of up to $10 \mathrm{kHz}$ (Nyquist frequency $5 \mathrm{kHz}$ ) given the available flow seeding, and this was used for all energy spectra measurements presented below

\section{Results and discussion}

\subsection{Centreline profiles}

LDA data were gathered for 10 NPR values in the range 1.28-3.0 to cover both subcritical and supercritical regimes. Figure 10a shows the measured mean axial velocity extracted from these measurements along the jet centreline for four selected NPR values. This clearly identifies the expected classical behaviour in the potential core zone for subcritical $(\mathrm{NPR}=1.45)$ and just choked $(\mathrm{NPR}=1.89)$ jets, both producing a constant centreline velocity-or nearly so, a small vena contract effect is still observed in spite of the exit parallel extension (nozzle exit velocity only $97 \%$ of isentropic and increase in centreline velocity by $\sim 1 \%$ outside nozzle). In contrast, for the two supercritical under-expanded cases (NPR $=2.32,3.00)$, embedded
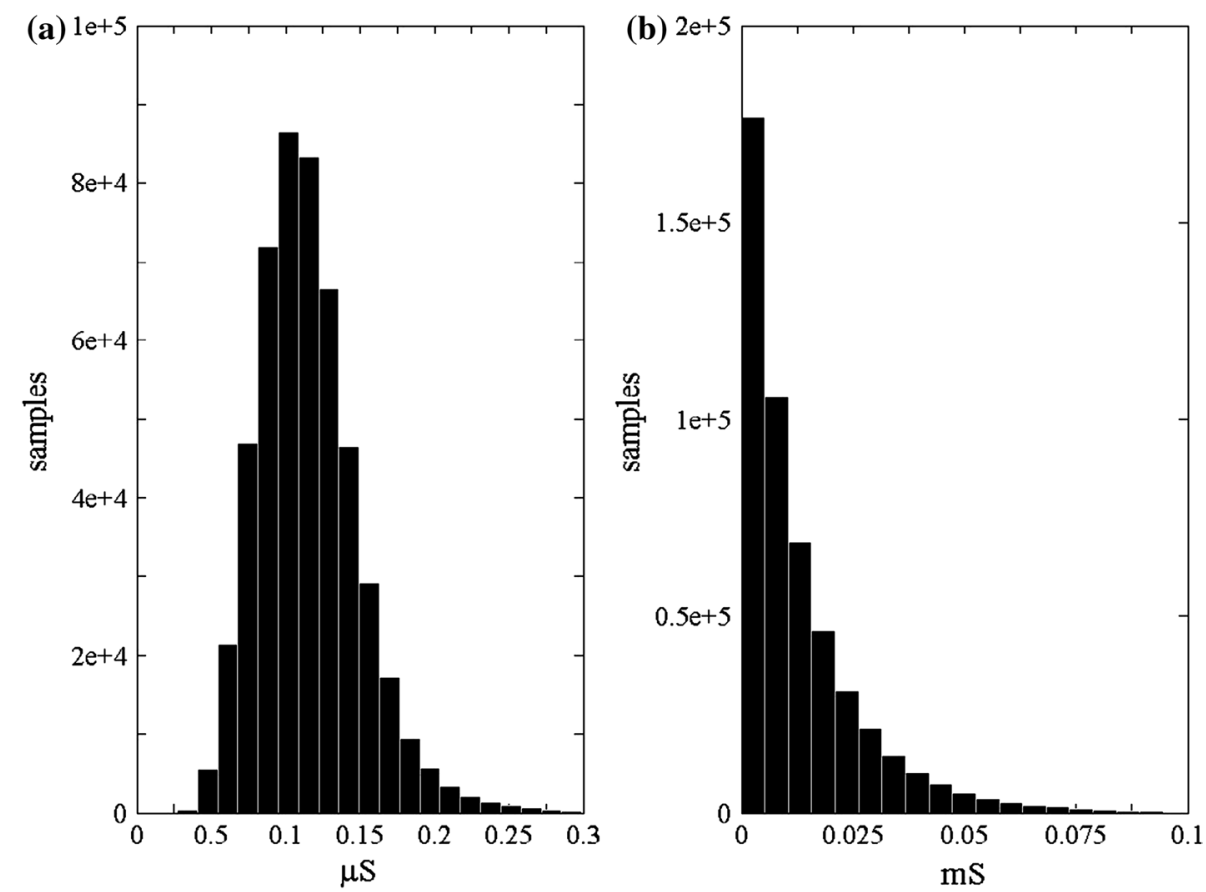
Fig. 10 Axial mean centreline velocity: a absolute and $\mathbf{b}$ normalised

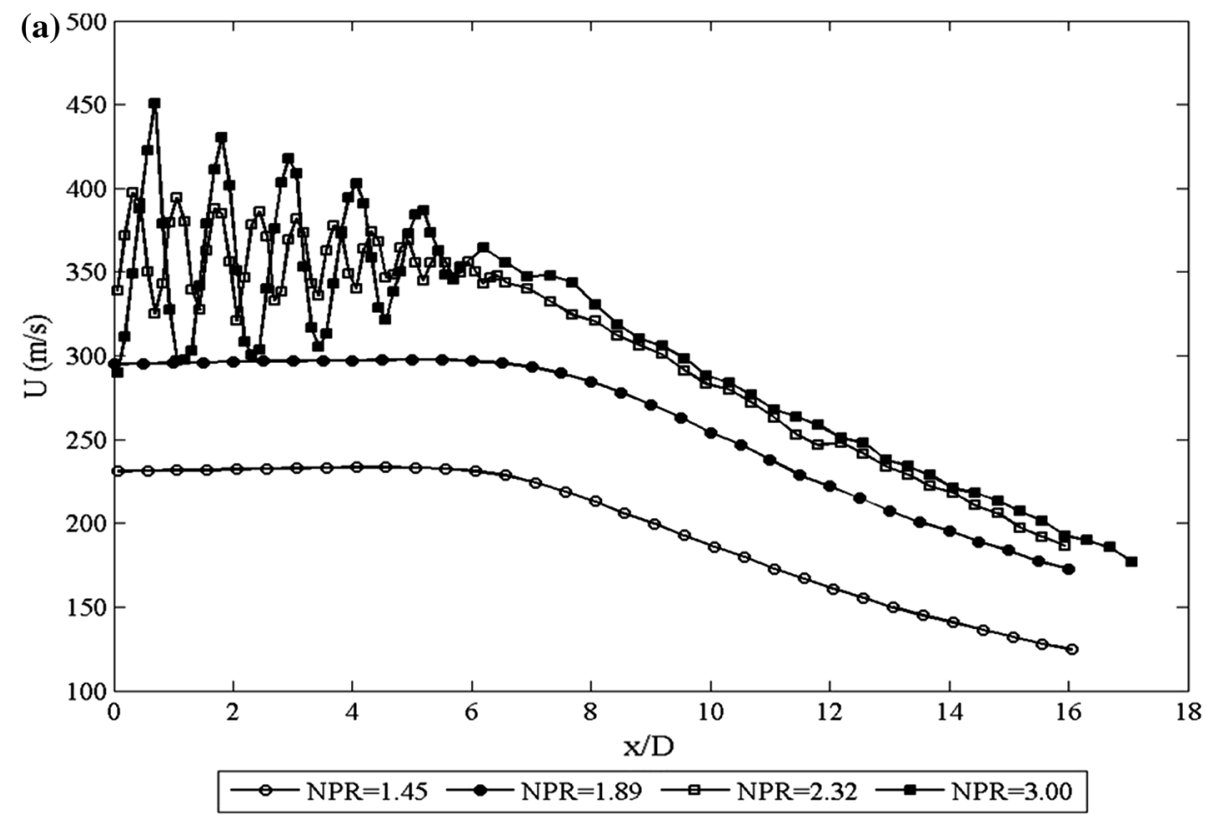

(b)

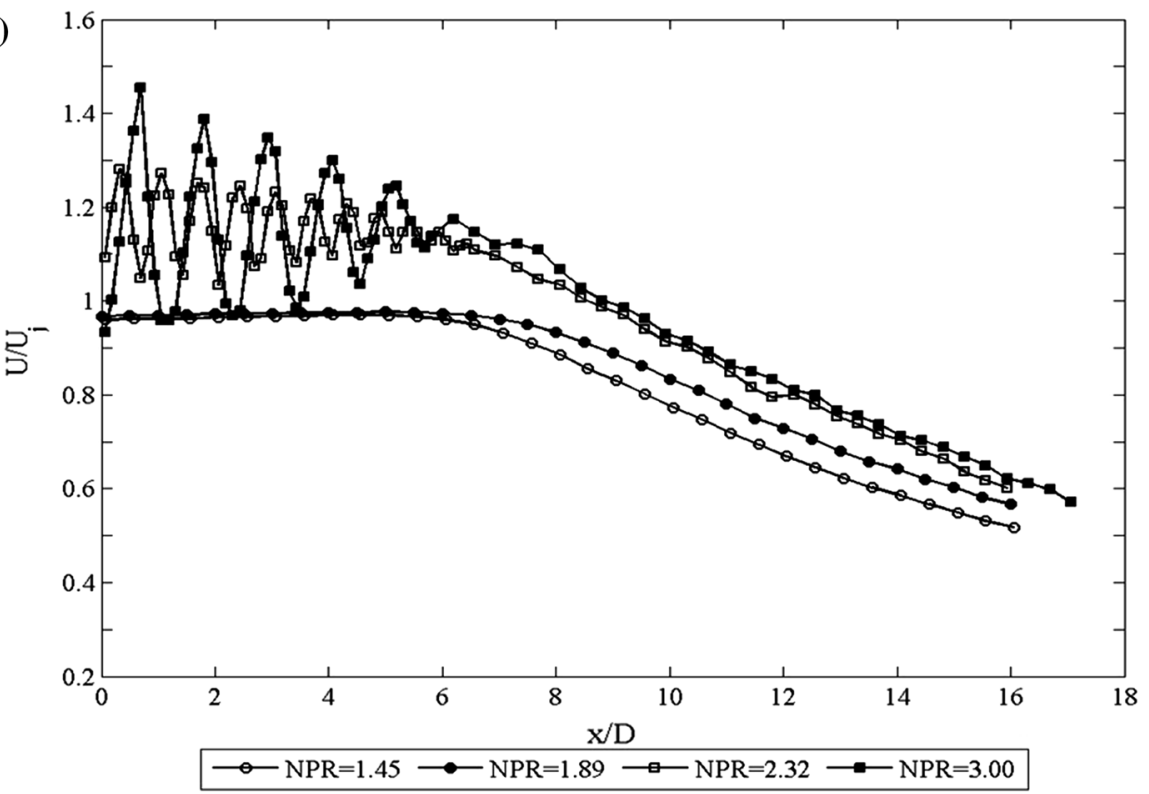

shock cells appear in the potential core zone, with the centreline velocity oscillating about an eventual fully expanded state. An estimate of the variation in potential core length with NPR is best revealed by plotting the data normalised by the isentropic nozzle exit velocity $U_{\mathrm{J}}$ (corresponding to $M=1.0$ for choked and supercritical cases). Using a value of $97 \%$ of the nozzle exit isentropic velocity to define potential core end, Fig. 10b indicates values of $6.04 \mathrm{D}$ for $\mathrm{NPR}=1.45,6.44$ for $\mathrm{NPR}=1.89,9.81 \mathrm{D}$ for $\mathrm{NPR}=2.32$, and $9.23 \mathrm{D}$ for NPR $=3$, showing a similar behaviour with jet Mach number as noted by Witze (1974) and Lau (1981), but with some non-monotonic effect due to improper expansion. The amplitude of velocity oscillation increases with NPR, and the number of shock cells decreases, 9 for $\mathrm{NPR}=2.32$ and 5 for NPR $=3$. The measured data show good spatial resolution of the shock structure, but it should be noted that the seeding particle lag when passing through the oblique shocks will have smeared this somewhat. The Stokes law analysis described above implies that the expected relaxation length of $1.1 \mathrm{~mm}$ will lead to smearing of this order of magnitude ( $2 \%$ in $x / D$ terms) in the measured shock locations and resolved gradients.

Turbulence characteristics along the jet centreline are shown in Fig. 11 for the same four NPRs; both axial and radial ( $z$-direction) rms intensities are shown, using the same normalisation as for the mean velocity. Three zones 
can be identified in the potential core region, most clearly in the lower NPRs, but on close inspection for all NPRs. For $0<x / D<2$, the rms remains close to that of the low level of turbulence in the core of the jet issuing from the nozzle exit. For $2<x / D<6$ (i.e. before potential core end), the rms rises but at a shallower gradient compared to the third zone, which begins (approximately) at potential core end $x / D \sim 6$. The rise in rms after $x / D \sim 6$ is due to the annular shear layer from the nozzle lip growing to meet the centreline, i.e. this is true shear-generated turbulence. For $2<x / D<6$, the increase in LDA-measured velocity fluctuations is not shear-generated turbulence but velocity unsteadiness arising due to two extra effects. Firstly static pressure fluctuations will be created within the jet core, induced by the streamwise motion and growth of large turbulent eddies within the shear layer. These cause a fluctuating inner edge of the annular shear layer and thereby induce static pressure and hence associated velocity fluctuations in
Fig. 11 a Axial and $\mathbf{b}$ radial centreline turbulence rms (normalised by $U_{\mathrm{J}}$ )
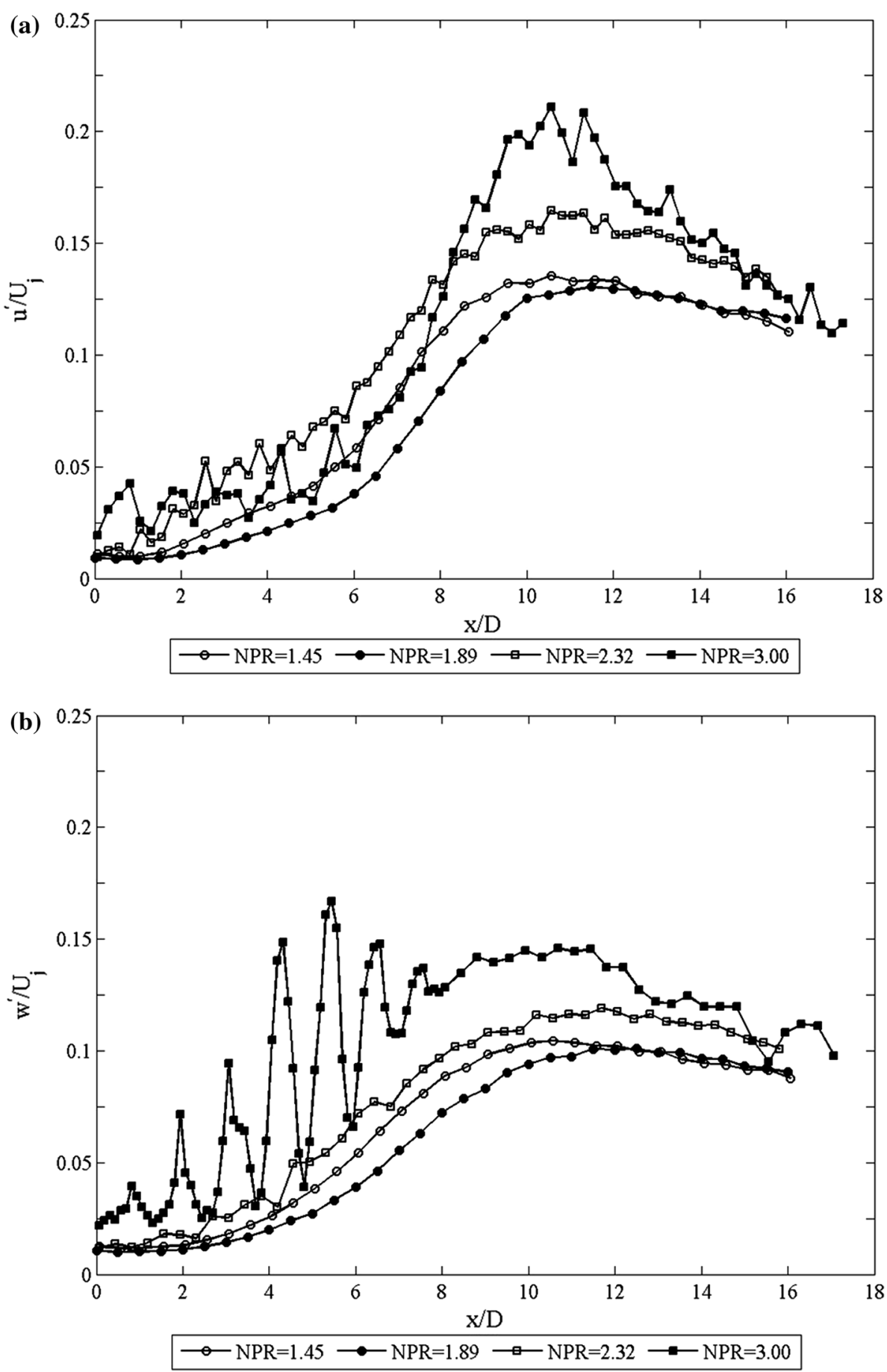

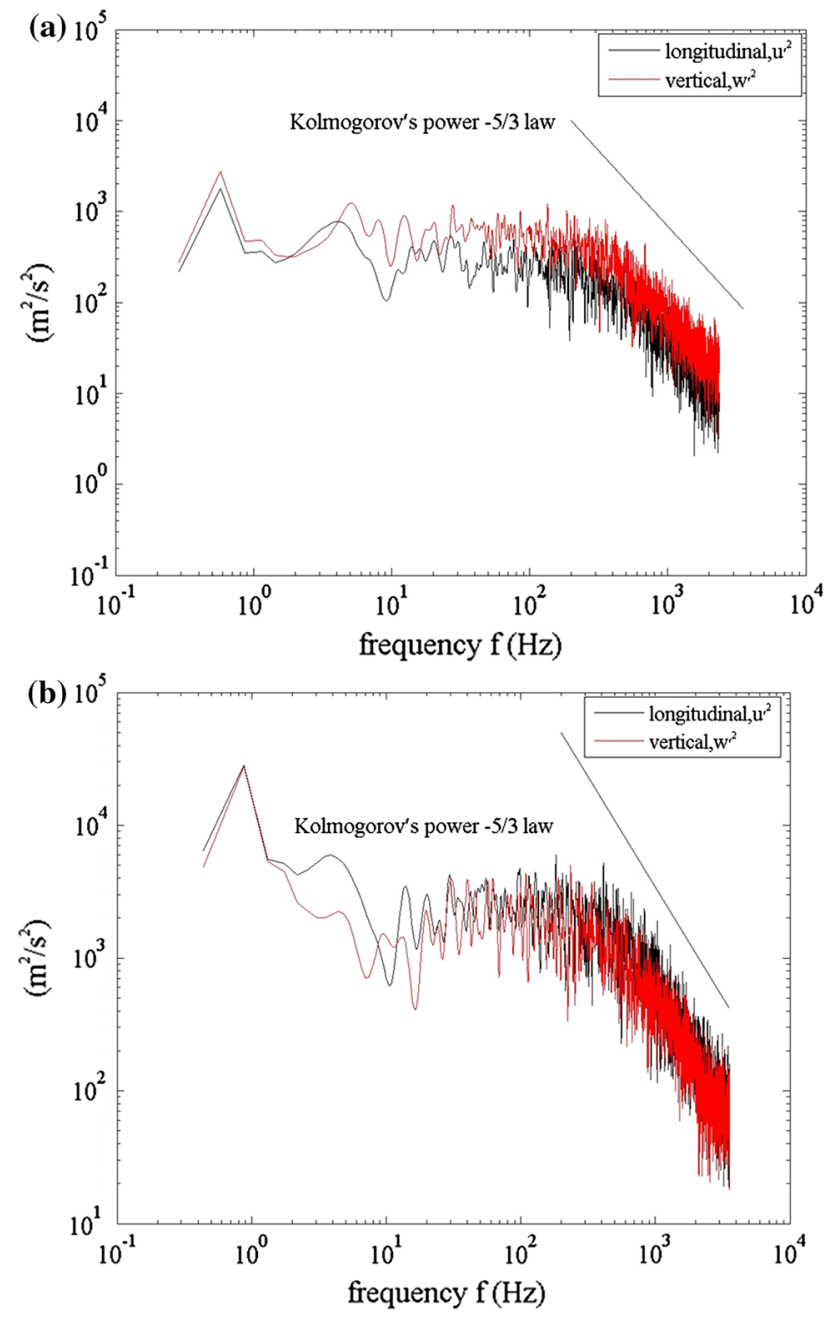

Fig. 12 Energy spectral density on jet centreline for NPR $=1.89$. a $x / D=0.06, \mathbf{b} x / D=3.3$

the jet core. Secondly (but only at high NPR) these irrotational fluctuations will also induce shock cell oscillation, which will then be seen as a further source of unsteady velocity by a stationary LDA measuring volume. The rms level oscillations in the two higher NPR results are coincident with the shock cell locations.

The peak turbulence location $(x / D=10-11)$ does not depend strongly on NPR, and the normalised peak level is similar for the two lower NPRs at $\sim 13 \%\left(u^{\prime}\right)$ and $10 \%\left(w^{\prime}\right)$; this increases for the two supercritical NPRs $2.32 / 3.00-16 / 20 \%\left(u^{\prime}\right)$ and $12 / 14 \%\left(w^{\prime}\right)$. By $x / D \sim 16$, the turbulence level is similar for all NPRs. Note also that the oscillations at the shock locations are significantly greater for the radial fluctuations; the most probable cause of this is lateral jet flapping induced by acoustic screech waves creating increased shock unsteadiness at NPR $=3.0$.
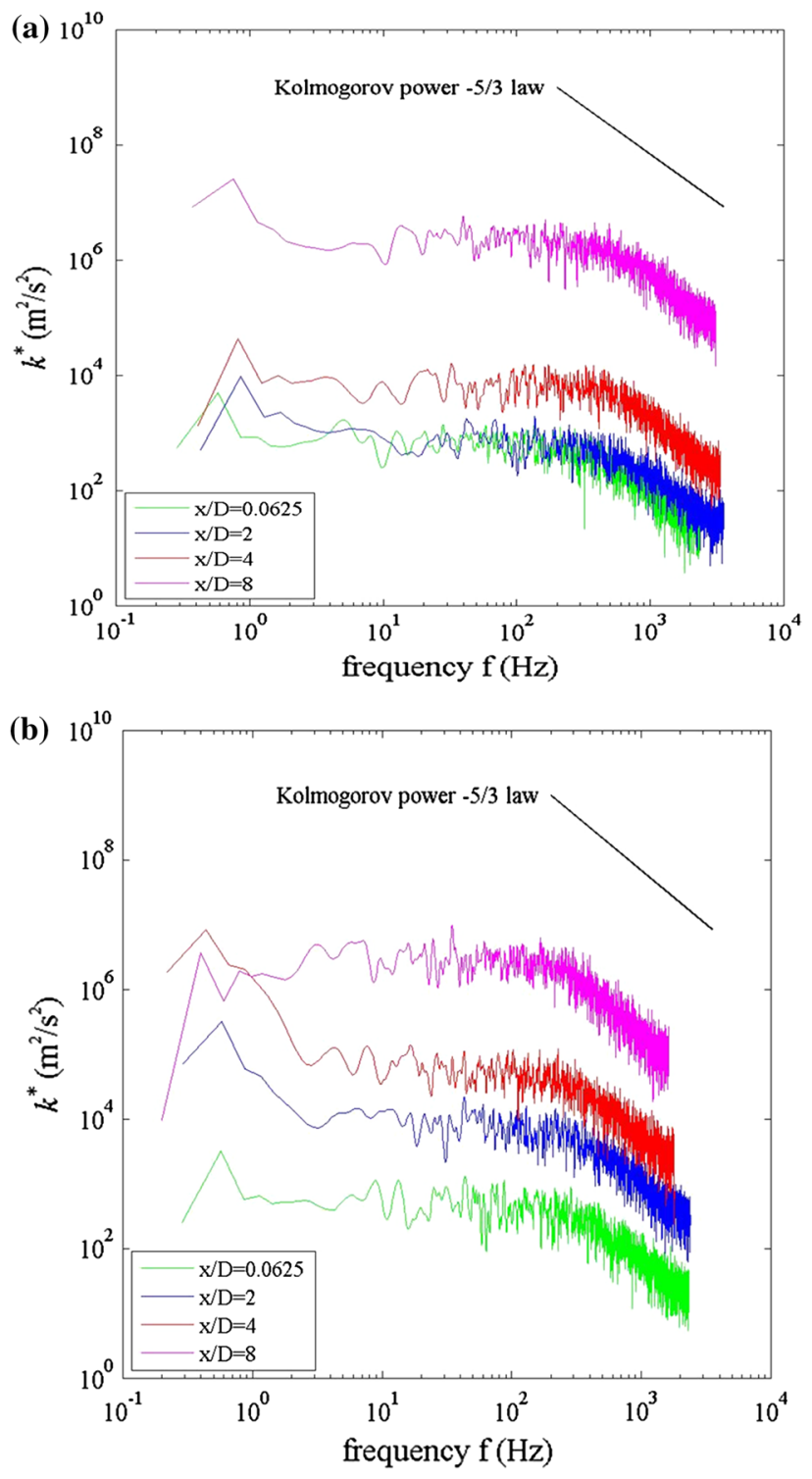

Fig. 13 Energy spectral density of turbulence energy $\left(k^{*}\right)$ on jet centreline, $\mathbf{a} \mathrm{NPR}=1.89, \mathbf{b} \mathrm{NPR}=2.32$

This causes the centreline turbulence anisotropy to vary; the ratio $u^{\prime} / w^{\prime}$ is at its lowest value at $\sim 0.76$ close to nozzle exit $(x / D=1.0)$ and increases to reach an asymptotic level maintained over $8.0<x / D<16.0$ of $\sim 1.35$. The dominance of radial to axial fluctuations in the early part of the jet on the centreline was confirmed by analysis of energy spectral density data from the LDA time series for $u$ and $w$ velocities, see Fig. 12 for the critical NPR $=1.89$. It is interesting to note that the spectra contain a $-5 / 3$ region, indicating that, although this is not high $R e$ locally shear-generated turbulence, since the inner shear layer edge oscillations are caused by large-scale eddies in the 
shear layer, the centrally induced fluctuations share a similar pattern, at least over the frequency range measured. By $x / D=3.3$, the axial and radial fluctuations are very similar, and this adjustment to a more usually expected ratio continues downstream.

Finally, Fig. 13 shows spectra for the turbulence energy $k^{*}$ evaluated at two NPRs and at several downstream centreline locations [NB, since only two components of the normal stress have been measured, turbulence energy is here characterised using an approximation that $\overline{v^{\prime 2}} \approx \overline{w^{\prime 2}}$, thus: $\left.k^{*}=0.5\left(\overline{u^{\prime 2}}+2 \overline{w^{\prime 2}}\right)\right]$. The energy content increases exponentially along the centreline but always displays an equilibrium decay range. Given the nature of the importance of unsteady processes in the above discussion, it will be difficult for any statistical RANS-based closure to provide an accurate description of the development of the turbulence in the jet near field (nozzle exit to potential core end).

\subsection{Lipline profiles}

Planar mixing layer studies have examined the effect of compressibility on shear layer turbulence-Elliot and Samimy (1990), Goebel and Dutton (1991), and Urban and Mungal (2001). The issue of the impact on turbulence anisotropy, i.e. the relative impact on axial-radial turbulence levels, has been noted, with some disagreement as to whether axial turbulence is affected. The current data have been examined in this context and are shown in Fig. 14, where the behaviour of axial and radial rms levels along the nozzle lipline is used to characterise
Fig. 14 a Axial and $\mathbf{b}$ radial turbulence rms along lipline
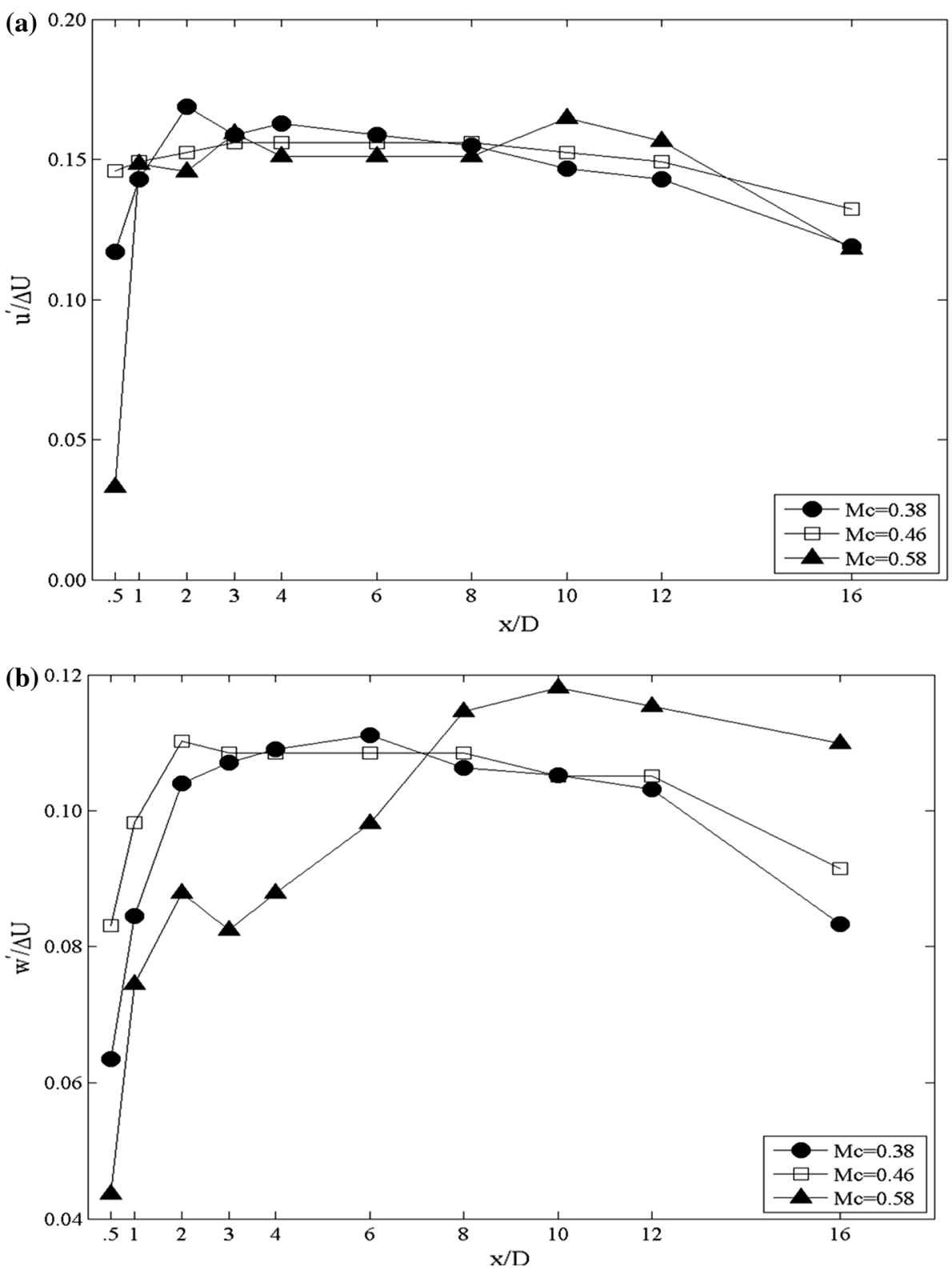
flow development. The conventional format of turbulence rms non-dimensionalised by the change in mean velocity across the shear layer is adopted to make comparisons between flow studies easier (e.g. $u^{\prime} / \Delta U-\mathrm{NB}$ for the present case, where for under-expanded NPRs the jet core velocity varies, an average value over the shock cell region has been used).

The variation over the first 16 nozzle diameters is shown in Fig. 14. Firstly it is evident that, unlike the planar case, the annular shear layer has insufficient development length to establish, and maintain, a truly self-similar state. Three zones may be identified in the flow development. The transition from boundary layer turbulence to free shear layer turbulence takes place in the first two diameters after nozzle exit; for the next $\sim 6$ jet diameters annular shear layer behaviour bordering an axisymmetric inner jet core zone follows; finally the influence of annular shear layer merging into a fully formed round jet cross section begins to take effect downstream of $x / D=10$. The strength of compressibility to which the shear layer is exposed has only small impact on the level of $u^{\prime} / \Delta U$; at $M_{\mathrm{C}}=0.58$ [see Eq. (2) for definition of $M_{\mathrm{C}}$ ] the compressible planar growth rate has reduced by approximately $1 / 3$ rd relative to the incompressible value (Barone et al. (2006)), but $u^{\prime} / \Delta U$ in the annular shear layer shows only slight evidence of reduction compared to lower $M_{\mathrm{C}}$. A much stronger effect of $M_{\mathrm{C}}$ is evident for the radial rms; the development of $w^{\prime} l$ $\Delta U$ at $M_{\mathrm{C}}=0.58$ shows considerably reduced levels in the annular shear layer before the transition to jet-like behaviour begins.
Fig. 15 Variation in peak a axial and $\mathbf{b}$ radial rms levels with $M_{\mathrm{C}}$
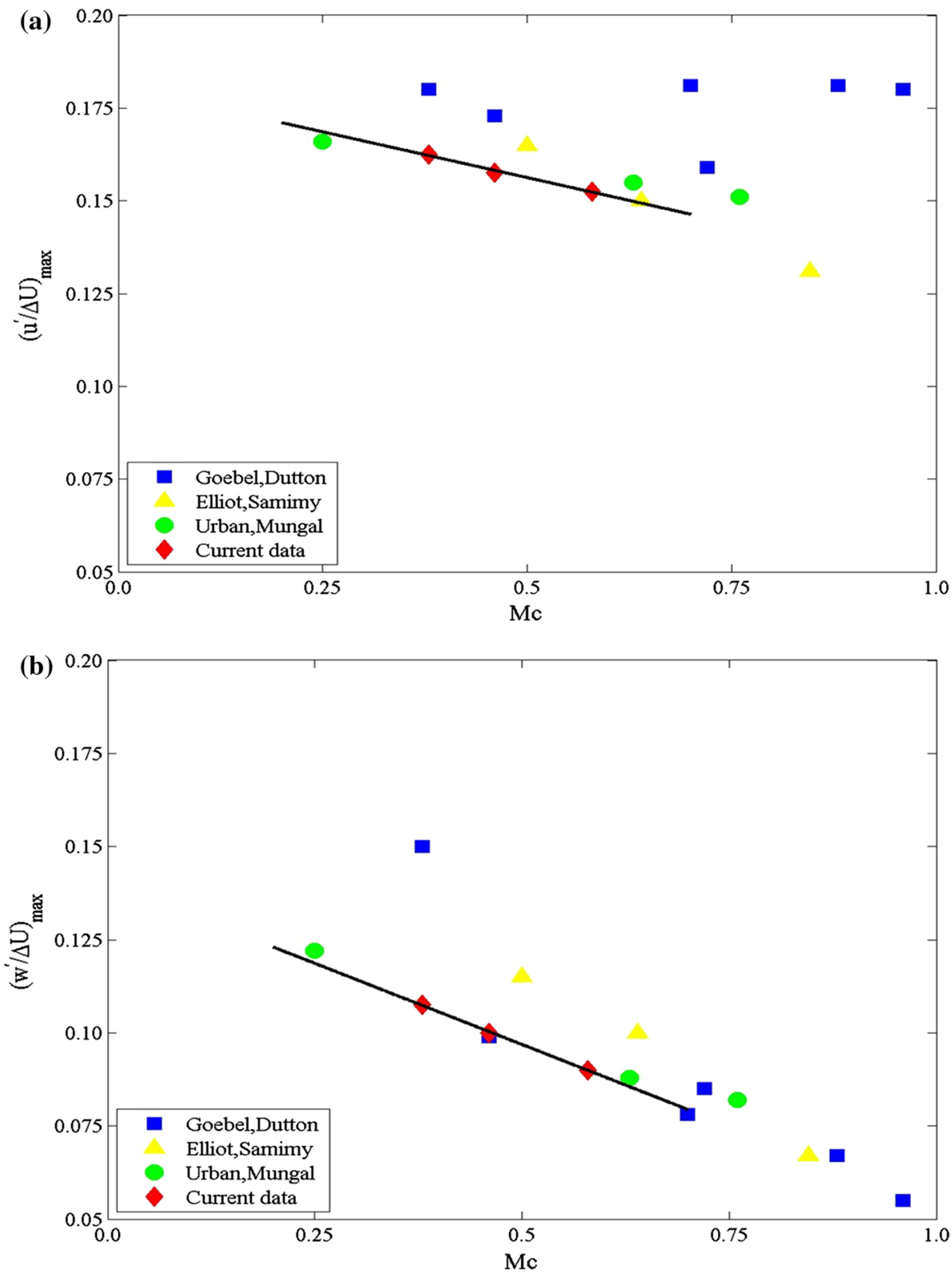
This is examined in more detail in Fig. 15, which shows the variation with $M_{\mathrm{C}}$ of the peak value of non-dimensional rms within the region of annular shear layer behaviour (an average value is taken for the current data over the region $1.0<x / D<6.0$ ). The present measurements generally fall in line with the trend identified by the three sets of planar data-the axial rms does decrease with increasing $M_{\mathrm{C}}$ but at a much smaller gradient (approximately one quarter) than that observed for the lateral rms. Note also that the line through the current data indicates that both axial and radial rms for the annular shear layer are at the lower end
Fig. 16 a Axial mean velocity, b turbulence energy $\left(k^{*}\right)$ radial profiles for NPR $=3.0$
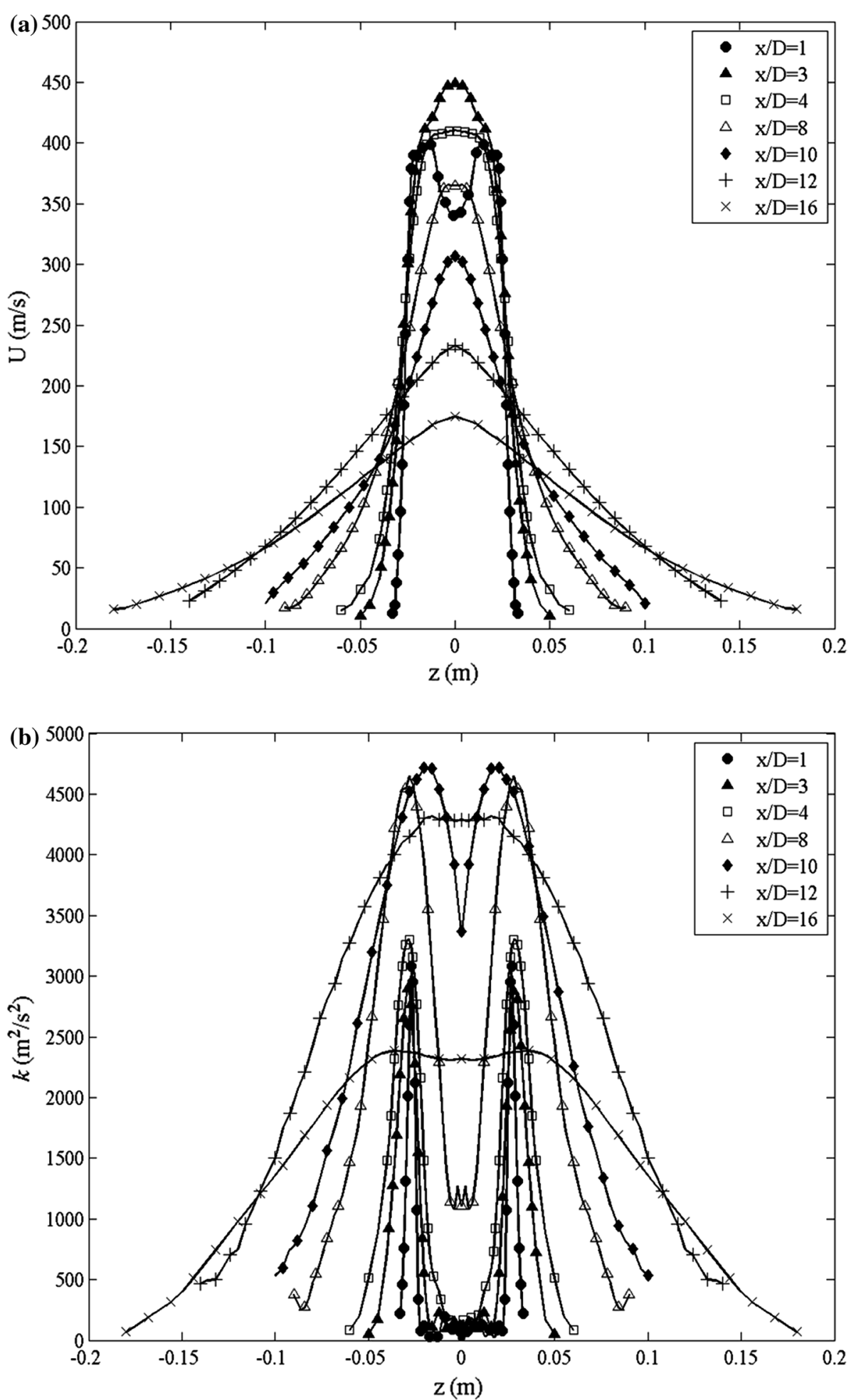
of the data scatter for the planar flow, suggesting a stronger suppression of turbulence at a given $M_{\mathrm{C}}$.

\subsection{Radial profiles}

Radial ( $z$-direction) profiles across the whole jet diameter were taken at ten axial stations for $1.0<x / D<16$. To illustrate the quantity and quality of the radial profile data taken, Fig. 16 shows mean axial velocity and turbulence energy $\left(k^{*}\right)$ profiles for the highest NPR tested (NPR $=3.0$ data at all other NPRs were of similar quality).

Measurements were taken over the full diameter of the jet to test axisymmetry, which is shown in Fig. 16 to be excellent. The peaks and troughs of velocity on the jet
Fig. 17 Axial mean velocity in similarity co-ordinates. a $\mathrm{NPR}=1.68, \mathbf{b} \mathrm{NPR}=3.0$
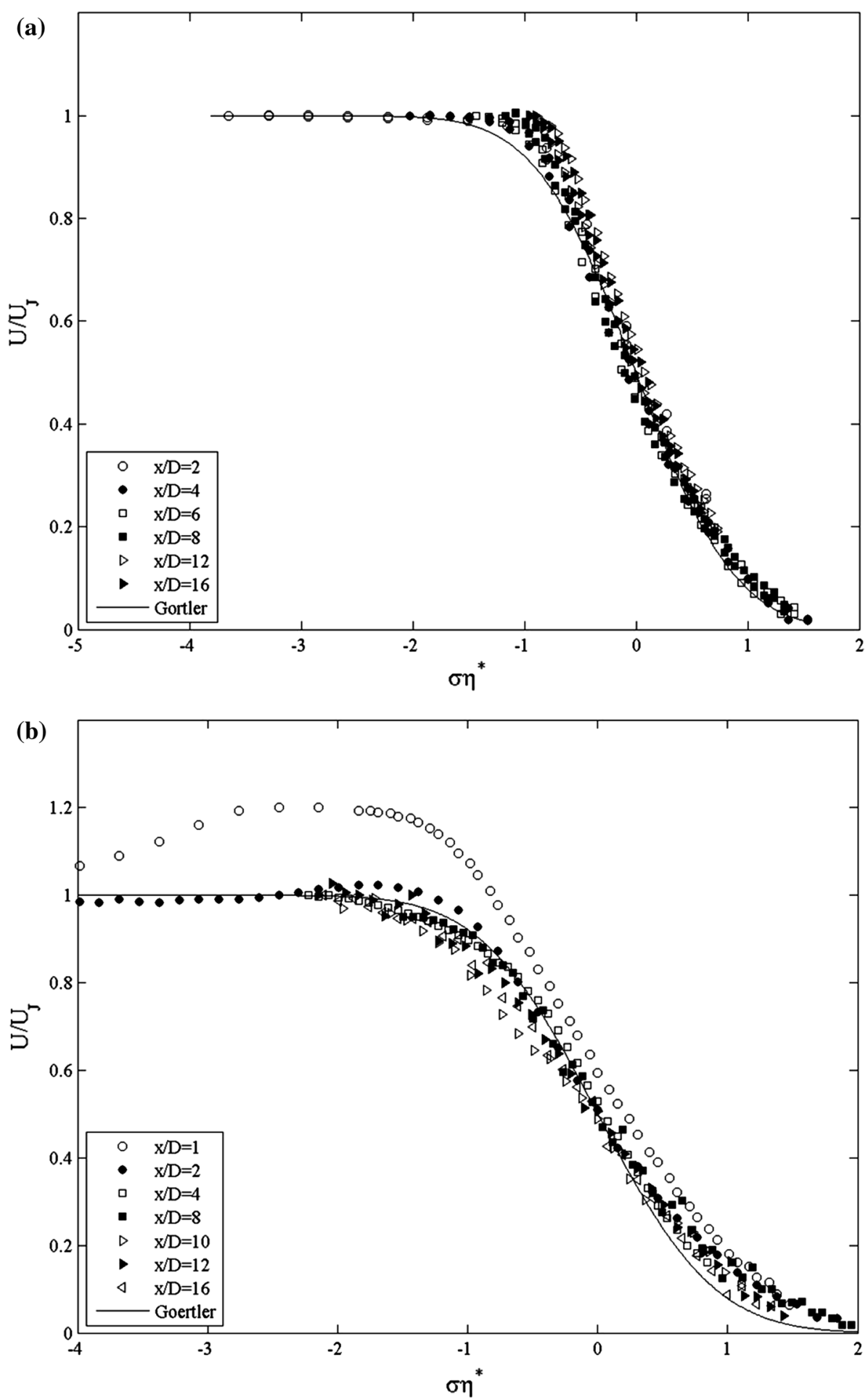
centreline at low $x / D$ correspond to different locations in the shock cells as visualised in Fig. 4. The resolution of the mean velocity gradients in the shear layer region will be important for assessment of growth rates, and this is seen to be more than adequate in Fig. 16. The rapid growth in $k^{*}$ in the annular shear layer is captured, with the peak value being reached on the nozzle lipline $(z=0.024 \mathrm{~m}$ or $\left.r / D_{\mathrm{J}}=0.5\right)$ at $\sim 10$ diameters downstream; thereafter, the peak energy level decreases as the jet decelerates in the transitional region before fully merged jet self-similarity is established. The peak axial rms moves to the centreline at $x / D=12.0$, but then moves slightly off axis as the turbulence develops to a self-similar jet-like shape.

To compare the current annular mixing layer measurements with previous data, comparison with the measurements of Lau et al. (1979) in a round jet was carried out. Lau et al. (1979) found that the mean velocity profile data could be best collapsed in terms of a fit to the Görtler error function profile for jet Mach numbers up to as high as $M_{\mathrm{J}}=1.37\left(\mathrm{NB}\right.$, the $M_{\mathrm{J}}>1$ data were obtained with convergent-divergent nozzles operating at their design NPR, i.e. all data considered by Lau et al. (1979) were properly expanded jets). The best-fit profile shape (for the Mach number range $0.3-1.4$ ) was written as:

$$
\begin{aligned}
\frac{U}{U_{\mathrm{J}}} & =0.5\left[1.0-\operatorname{erf}\left(\sigma \eta^{*}\right)\right], \\
\sigma & =10.7 /\left(1.0-0.273 M_{\mathrm{J}}^{2}\right), \eta^{*}=\left(r-r_{0.5}\right) / x
\end{aligned}
$$

where $r_{0.5}$ refers to the radial location where local mean velocity is $0.5 U_{\mathrm{J}}$. Figure 17 shows the present data for the lowest and highest jet Mach numbers tested $(\mathrm{NPR}=1.68$ and 3.0) presented in this fashion; the fit is excellent for the subsonic jet (in fact for all shock-free NPRs measured), but deviations from the profile become evident as soon as the jet expansion contains shocks.

To focus attention on the annular shear layer growth region, and to account (in part) for differences caused at various NPRs, non-dimensionalised radial profiles [now using the local measured centreline axial velocity $\left.\left(U_{\max }\right)\right]$ are illustrated for mean axial velocity at four axial locations $(x / D=0.5,1.0,4.0$ and 8.0) and for 4 NPRs in Fig. 18. For axial rms and turbulent shear stress, and at 3 NPRs, Figs. 19 and 20 show profiles at $x / D=0.5$ and 4.0. Figure 18 shows that there are obvious differences in the mean velocity at the first two stations at the two higher NPRs near the centreline caused by a fixed $x / D$ axial location falling in different regions of expansion/compression waves as shock cell length alters with NPR (the fixed $x / D$ values marked in Fig. 4 at NPR of 2.32 and 3.0 illustrates this well). In the shear layer region itself the nondimensional profiles are remarkably similar for all NPRS, although at the first location for the NPR $=3.0$ case, where the shock cells are stronger than at NPR $=2.32$, the shear layer region is shifted radially outwards due to the curvature of the jet/ambient boundary at high NPR. At the next station downstream these shock-induced jet core effects have now caused both higher NPR cases to differ from the two subsonic cases. By $x / D=4.0$, the two higher NPR profiles still depart from the subcritical flow development, but now straddle the subsonic profile, with the higher NPR moving inboard. Finally, at $x / D=8.0$ Fig. $18 \mathrm{~d}$ shows that
Fig. 18 Axial mean velocity radial profiles for various NPR at $x / D$. a 0.5, b $1.0, \mathbf{c} 4.0, \mathbf{d} 8.0$
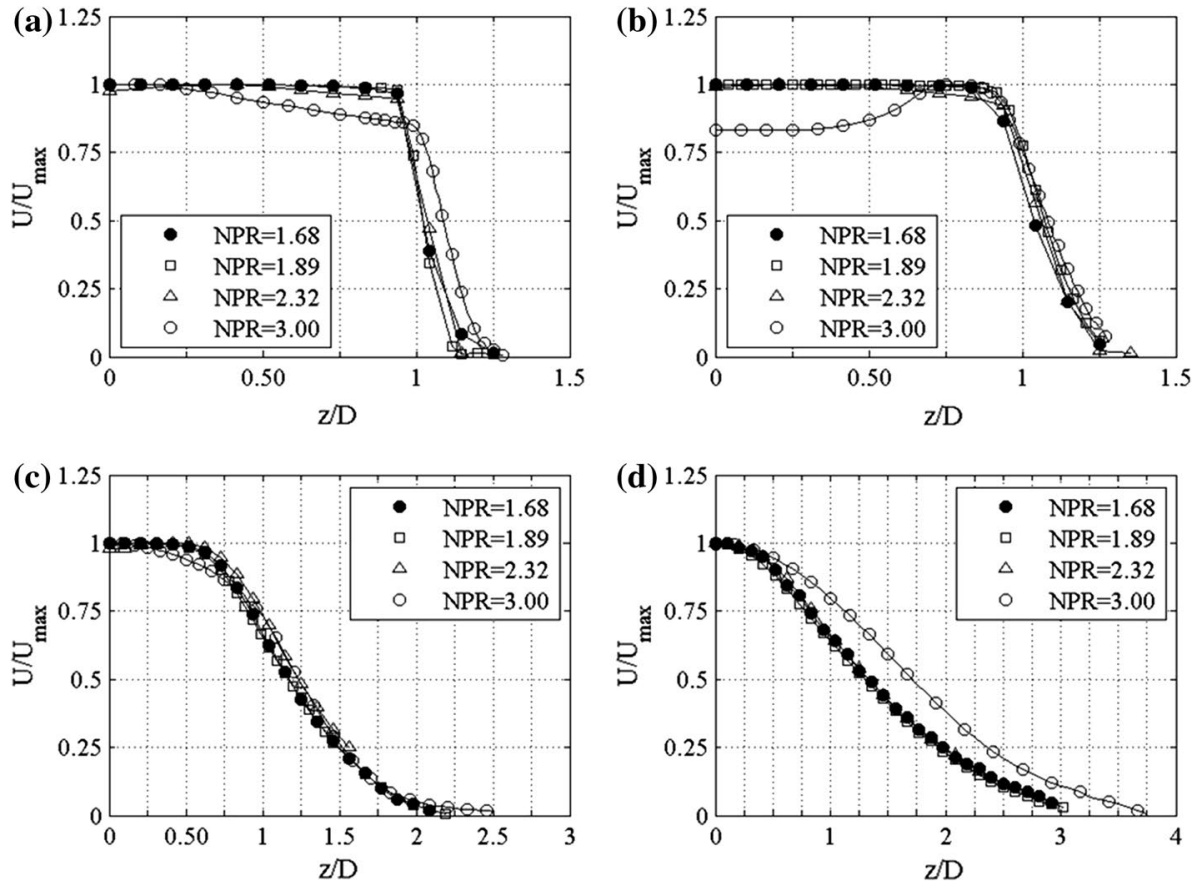
Fig. 19 Axial turbulent rms radial profiles for various NPR at $\mathbf{a} x / D=0.5, \mathbf{b} x / D=4.0$
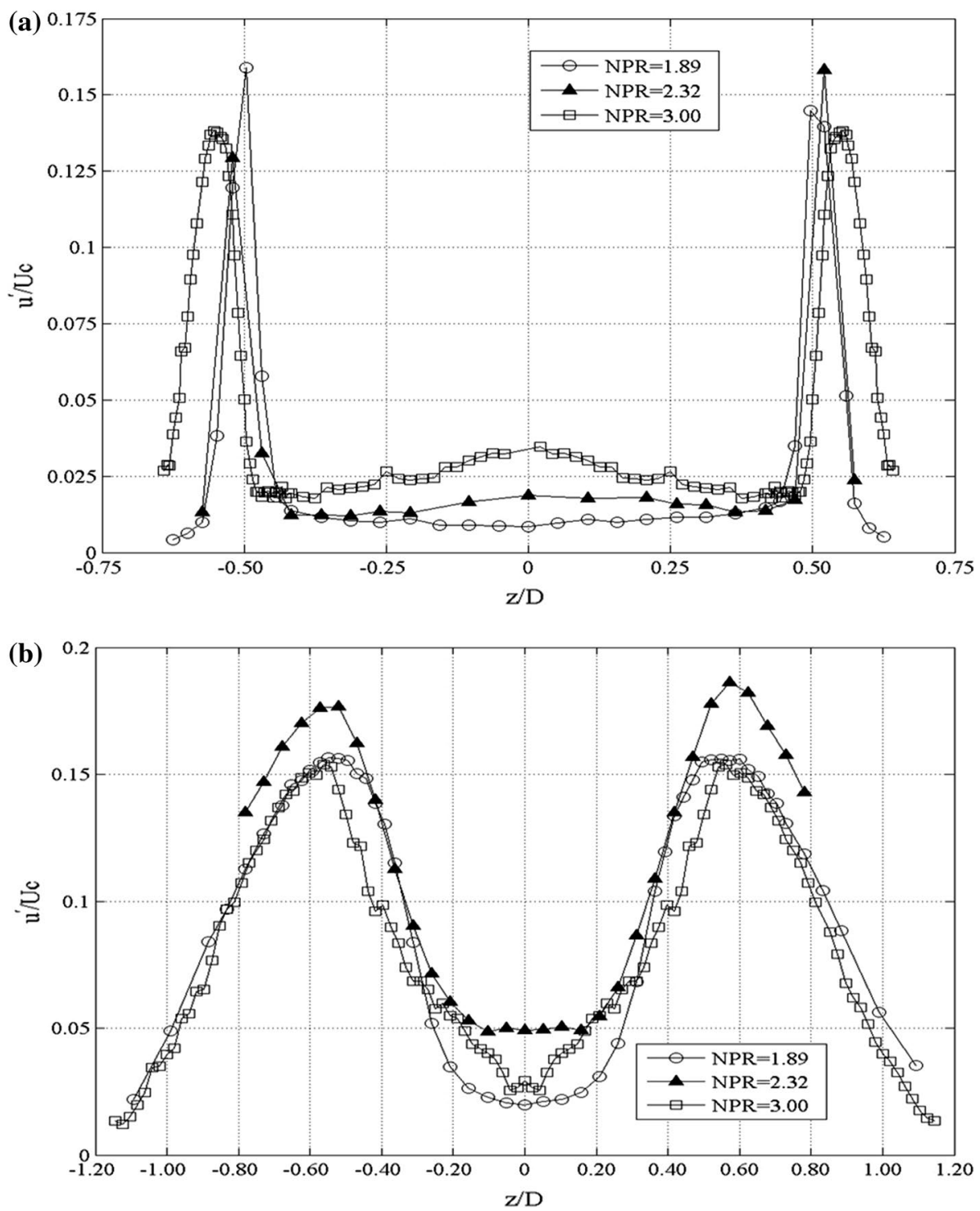

the profiles for the NPR $=2.32$ and the two subsonic NPRs overlap quite closely, but the NPR $=3.0$ profile has now shifted outboard again. These profiles indicate how the presence of the inviscid shock cells in the under-expanded cases influences the shear layer region as well as any compressibility-influenced spreading.

With regard to annular shear layer turbulence development, Figs. 19 and 20 display some differences in peak rms and shear stress levels, with in general the NPR $=2.32$ case showing the highest value. The levels in the centreline region are almost an order of magnitude lower at the first location and, as noted above, differences are dominated by shock cell-induced unsteady motions. The peak shear stress at $x / D=0.5$ highlights the very thin nature of the shear layer at this early stage of development; near the centreline at $x / D=4.0$ the shape of the shear stress profile is very different for the highest NPR compared to the other cases, since for this case the centreline rms data in Fig. 11 have indicated that the shock cell influence on the lateral velocity fluctuation is very strong.

\subsection{Annular shear layer growth rate analysis}

The radial profiles measured at the ten axial stations in the region $0<x / D<16$ and for both subcritical and underexpanded NPRs were post-processed to extract data on compressibility-affected growth rates. The thickness of the annular mixing layer was evaluated using the vorticity thickness approach (Brown and Roshko 1974), which for the present case leads to following expression (both $\mathrm{U}_{\mathrm{C}}$ and the maximum gradient evaluated at each axial station):

$\delta(x)=\frac{U_{\mathrm{C}}}{(\partial U / \partial z)_{\max }}$ 
Fig. 20 Turbulent shear stress radial profiles for various NPR at $\mathbf{a} x / D=0.5, \mathbf{b} x / D=4.0$
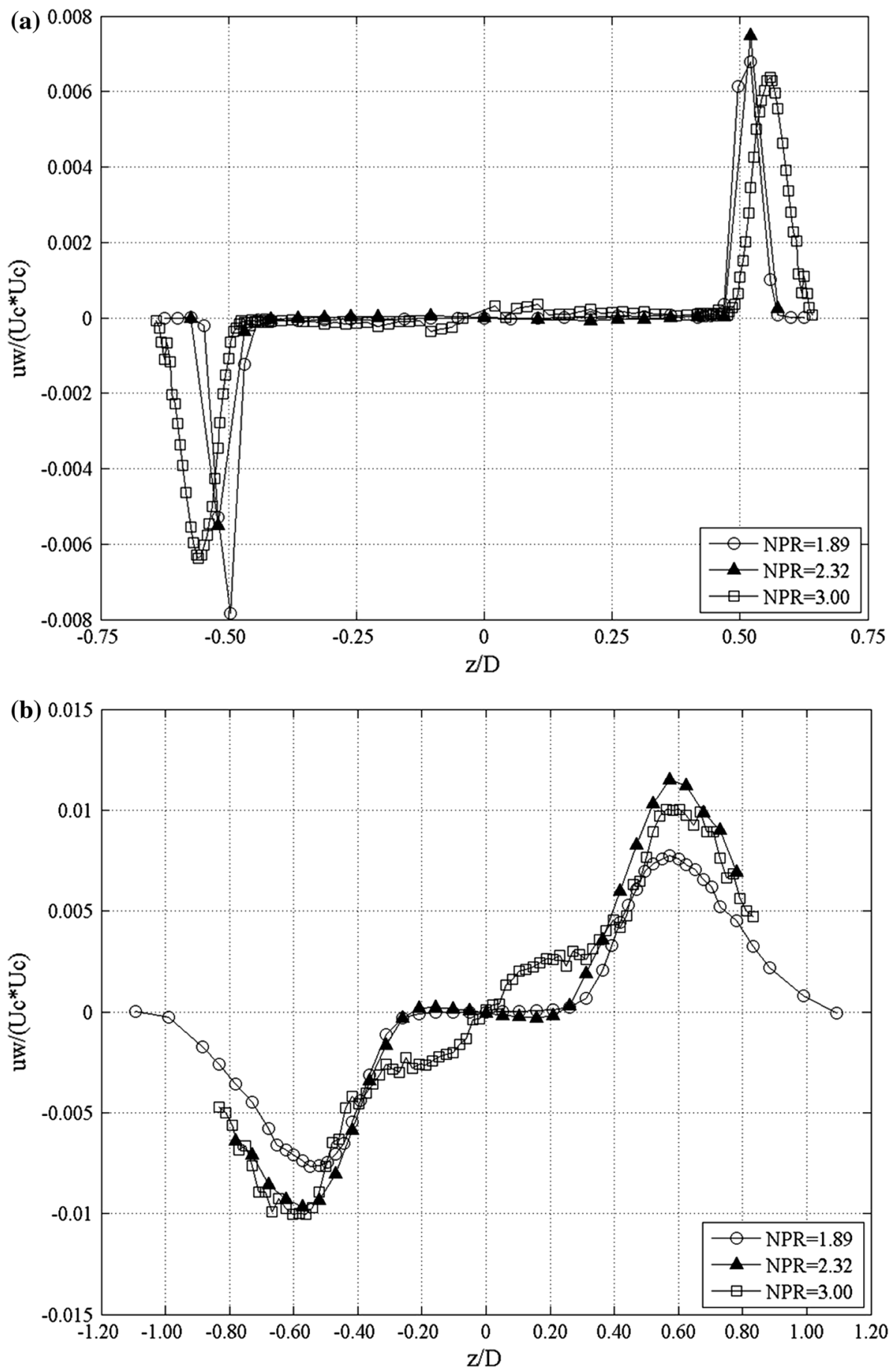

An example of evaluation of the maximum gradient is shown in Fig. 21a for NPR $=1.45$, to indicate the high accuracy with which the maximum gradient value could be evaluated. A least-squares best-fit straight line was fitted to the shear layer widths $(\delta)$ evaluated, as shown in Fig. 21b for NPR $=2.32$; note that even for under-expanded NPR cases a two-region straight line characteristic was always present; the first clearly corresponded to the annular shear layer zone and the second to the merging and near-field developing jet zone. The quality of the straight line fits was measured by a correlation coefficient quantifying the overall deviation of the measured points from a straight line fit and was always greater than $99 \%$. The accuracy of the linear gradient (i.e. the growth rate $\delta^{\prime}$ ) was similar to that shown in Fig. 21 for all NPRs and at all $M_{\mathrm{C}}$. It is the first region values which are extracted here as annular shear layer growth rate $\delta^{\prime}$ and non-dimensionalised by the incompressible (i.e. zero $M_{\mathrm{C}}$ ) value $\delta_{0}^{\prime}=0.166$. The current 
Fig. 21 a Evaluation of maximum velocity gradient. b Annular shear layer growth rate
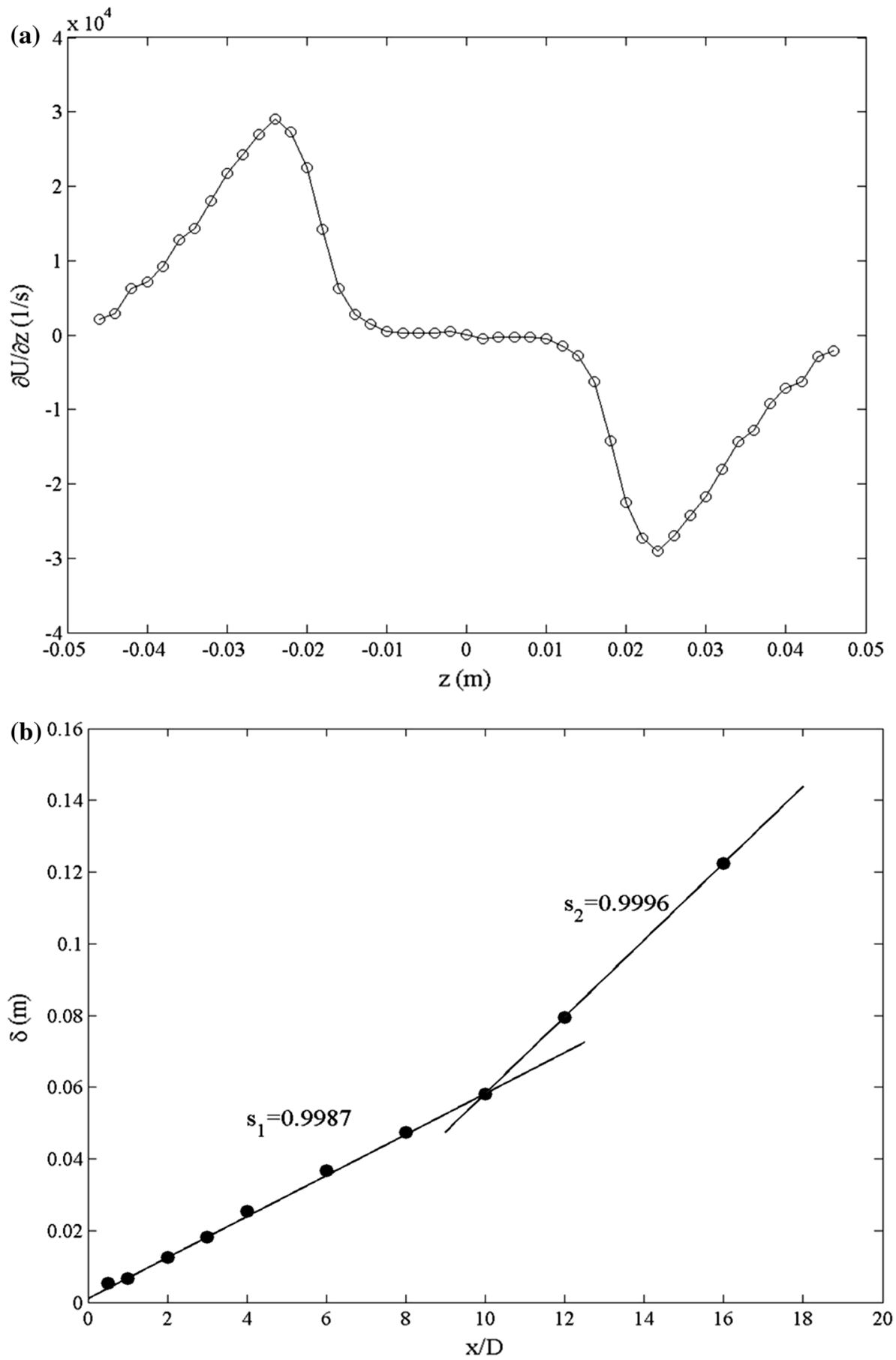

data were then entered on the classical compressibility factor plot produced for the planar shear layer in Barone et al. (2006) (NB, the LDA-measured axial velocity on the centreline allowed the static temperature to be evaluated from an adiabatic gas dynamic relation to calculate the speed of sound in order to evaluate $M_{\mathrm{C}}$ ). Figure 22 shows the resulting comparison.

It is clear from Fig. 22 that the annular shear layer data from the current round jet experiment do not experience similar growth rate suppression as the planar shear layer, when the jet is operated at a range of NPRs leading to a similar variation in $M_{\mathrm{C}}$ for which the planar mixing layer exhibits strong compressibility reduction. The present experiments and the experiments of Lau et al. (1979), both carried out using non-intrusive instrumentation in axisymmetric jets, agree well. The onset of compressibility reduction in growth rate is seen to begin earlier in the annular shear compared to planar shear layer data. At similar values 
Fig. 22 Compressibilityaffected shear layer growth rate

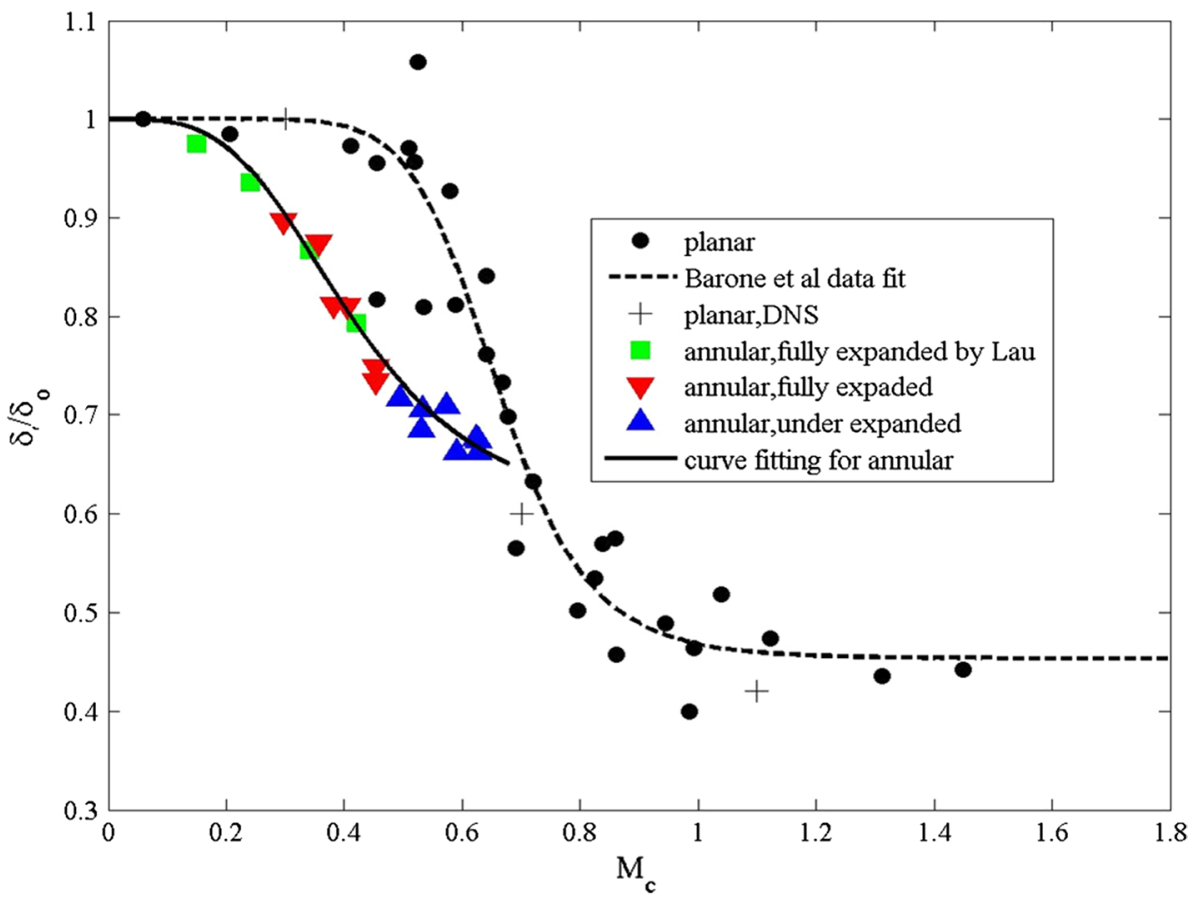

of $M_{\mathrm{C}}$ the present data indicate that annular growth rates are suppressed more than in the equivalent planar shear layer for $M_{\mathrm{C}}$ values up to $\sim 0.6$. This is consistent with the larger suppression of peak turbulence rms levels noted in Fig. $15 . M_{\mathrm{C}}=0.6$ seems also to be virtually an asymptotic value for a convergent-only nozzle as increasing NPR from 2.32 to 3.00 had little effect The most likely reasons for this behaviour are: (i) as noted in the lipline profiles, the annular shear layer on the edge of a round jet exhibits stronger turbulence suppression, (ii) never sustains a truly self-similar state for long compared to the planar case, (iii) before entering a transition to jet-like behaviour, and (iv) for higher $M_{\mathrm{C}}$, if this involves under-expanded jets, the presence of the shock cell regions on the inner edge of the shear layer causes significant shear layer profile shapes than in planar mixing layers at the same level of $M_{\mathrm{C}}$.

\section{Summary and conclusions}

The topic of compressibility-induced reduction in turbulent-free shear layer growth rate has been studied intensively for at least four decades and is still a current subject for DNS and LES CFD studies. The vast majority of this research has been concentrated on planar mixing layers. The most common practical application of this phenomenon is in aerospace engineering, driven by the need for improved propulsion nozzle designs for low noise (civil) and low observability (military). In such applications the shear layer is most commonly of annular configuration, formed at the interface between high-speed round propulsion jet and ambient. Annular or axisymmetric high-speed shear layers have, however, received little attention in this context. In addition, there has been very little work to examine the effects of improperly expanded jets on compressible mixing layer development. The work reported here has thus focussed on an experimental study of the axisymmetric annular shear layer behaviour associated with convergent conical nozzle jet plumes over a range of NPR, including moderately under-expanded cases.

Detailed LDA measurements were taken with good axial and radial spatial resolution for both mean and turbulence properties. Post-processing of the data allowed the effect of compressibility, characterised as in planar mixing layer studies by the convective Mach number $M_{\mathrm{C}}$, to be examined both in terms of the annular shear layer development, and the near field of the merged jet just downstream of potential core end, for a range of subsonic as well as moderately expanded NPRs. The flow characteristics were compared with planar shear layer data from the literature, and, in agreement with the observations of Elliot and Samimy (1990), and Urban and Mungal (2001) and in contrast to the data of Goebel and Dutton (1991), the effect of $M_{\mathrm{C}}$ on turbulence was confirmed as reducing both axial and radial turbulence intensities in the shear layer from typical incompressible levels, but with a much stronger reduction in the lateral (radial) intensity. Investigation of the shear layer mean velocity profile shape showed that this collapsed well onto a previously suggested self-similar profile for high-speed jets, except when the jet core contained shock cell features when significant profile shifts were observed. Specifically in terms of the reduction in shear layer growth 
rate caused by compressibility, the present data were shown to be in good agreement with the only other experimental survey of annular shear layers bordering round jets. However, the annular shear layer data did not collapse on the best-fit curve of all existing planar data. The indication was that compressibility effects in annular shear layers began at a lower convective Mach number and displayed stronger growth rate reduction than for planar shear layers at the same effective $M_{\mathrm{C}}$. The explanation for this difference is twofold. Firstly, unlike planar shear layers, axisymmetric jet shear layers do not experience long regions of self-similarity; initially, they undergo transition from a boundary layer to a free shear layer, and soon thereafter they transition again and develop a merged jet character. Secondly, high $M_{\mathrm{C}}$ flows in jets are often accompanied by improperly expanded shock cell features and their presence also alters the profile shape. Since annular shear layers are the most practically common occurrence of compressibility reduction in aerospace engineering, it is suggested that the current measurements represent the most comprehensive data suitable for CFD validation studies.

Acknowledgments This work was funded by EPSRC (Grant No. GR/S27467/01) via the MSTTAR DARPS consortium.

Open Access This article is distributed under the terms of the Creative Commons Attribution 4.0 International License (http://creativecommons.org/licenses/by/4.0/), which permits unrestricted use, distribution, and reproduction in any medium, provided you give appropriate credit to the original author(s) and the source, provide a link to the Creative Commons license, and indicate if changes were made.

\section{References}

Barone MF, Oberkampf WL, Blottner FG (2006) Validation case study: prediction of compressible turbulent mixing layer growth rate. AIAA J 44:1488-1497

Barre S, Quine C, Dussauge JP (1994) Compressibility effects on the structure of supersonic mixing layers: experimental results. J Fluid Mech 259:47-78

Batten P, Craft TJ, Leschziner MAL, Loyau H (1999) Reynolds stress transport modelling for compressible aerodynamics applications. AIAA J 37:785-796

Behrouzi P, McGuirk JJ (2009) Effect of tabs on rectangular jet plume development. AIAA J Propuls Power 25:930-939

Bellaud S, Barre S, Bonnet J-P (1999) Experimental study of annular supersonic mixing layers: turbulent kinetic energy budget. In: Proceedings of 1st International TSF Symposium

Birch SF, Eggers JM (1972) A critical review of the experimental data for developed free turbulent shear flows. In: NASA technical report SP-321

Bridges J, Wernet M (2003) Measurements of the aeroacoustic sound source in hot jets. In: 9th AIAA/CEAS aeroacoustics conference, AIAA 2003-3130

Bridges J, Wernet M (2010) Establishing consensus turbulence statistics for hot subsonic jets. In: 16th AIAA/CEAS aeroacoustics conference, AIAA 2010-3751
Brown CA, Bridges J (2006) Small hot jet acoustic rig validation. NASA TM-2006/214234

Brown GL, Roshko A (1974) On density effects and large structures in turbulent mixing layers. J Fluid Mech 64:775-781

Day MJ, Reynolds WC, Mansour NN (1998) The structure of the compressible reacting mixing layer: insights from linear stability analysis. Phys Fluids 10:993-1006

El Baz AM, Launder BE (1993) Second-moment modelling of compressible mixing layers. In: Rodi WA, Martinelli F (eds) Engineering turbulence modelling and measurements, 2nd edn. Elsevier Press, Amsterdam, pp 63-72

Elliot GS, Samimy M (1990) Compressibility effects in free shear layers. Phys Fluids 2:1231-1240

Ess PR, Leschziner MAL (2005) Modelling compressible and underexpanded jets with 2nd moment closure. In: Proceedings of TSFP 5, Munich, Germany

Feng T, McGuirk JJ (2006) LDA measurements of underexpanded jet flow from an axisymmetric nozzle with tabs. In: Proceedings of 3rd AIAA flow control conference, AIAA 2006-3702

Feng T, McGuirk JJ (2007) LDA measurements of heated and unheated underexpanded jets from axisymmetric convergent nozzles. In: Proceedings of 18th ISABE conference, ISABE-2007-1322

Freund JB, Lele SK, Moin P (2000) Compressibility effects in a turbulent annular mixing layer, Part 1: turbulence and growth rate. J Fluid Mech 421:229-267

Fu S, Li Q (2006) Numerical simulation of compressible mixing layers. Int J Heat Fluid Flow 27:895-901

Fujiwara H, Matsuo Y, Arakawa C (2000) A turbulence model for the pressure-strain correlation term accounting for compressibility effects. Int J Heat Fluid Flow 21:354-358

Goebel SG, Dutton JC (1991) Experimental study of compressible turbulent mixing layers. AIAA J 29:538-546

Gomez G, Girimaji G (2013) Towards second-moment closure modelling of compressible shear layers. J Fluid Mech 733:325-369

Guitton, A., Tinney, C. E., Jordan, P. (2007) Measurements in a coaxial subsonic jet. In: 45th aerospace sciences meeting, AIAA 2007-0015

Lau JC (1981) Effects of exit Mach number and temperature on mean flow and turbulence characteristics in round jets. J Fluid Mech 105:193-218

Lau JC, Morris PJ, Fisher MJ (1979) Measurements in subsonic and supersonic free jets using a laser velocimeter. J Fluid Mech 93:1-27

Le Ribault C (2005) Large eddy simulation of compressible mixing layers. Int J Dyn Fluids 1:87-111

Lejeune C, Kourta A (1997) Modelling of extra compressibility terms in high speed turbulent flows. In: Proceedings of 11th TSF symposium, pp P3.71-P3.76

Lepicovsky J (1990) Total temperature effects on centreline Mach number characteristics of free jets. AIAA J 27:12-718

Lessen M, Fox J, Zien H (1966) Stability of the laminar mixing of two parallel streams with respect to supersonic disturbances. J Fluid Mech 925:737-742

Long DF (2005) Effect of nozzle geometry on turbofan shock cell noise at cruise. In: 43rd AIAA aerospace sciences meeting, AIAA-2005-998

McLaughlin DK, Tiedermann WG (1973) Biasing correction for individual realisation of laser anemometer measurements in turbulent flow. Phys Fluids 16:2082-2088

Melling A (1997) Tracer particles and seeding for particle image velocimetry. Meas Sci Technol 8:1406-1416

Olsen MG, Dutton JC (2003) Planar velocity measurements in a mildly compressible mixing layer. J Fluid Mech 486:51-77

Pantano C, Sarkar S (2002) A study of compressibility effects in the high-speed turbulent shear layer. J Fluid Mech 451:329-371 
Papamoschou D, Roshko A (1988) The compressible turbulent shear layer: an experimental study. J Fluid Mech 197:453-477

Reeder MF, Samimy M (1997) The evolution of a jet with cortex generating tabs: real-time visualisation and quantitative measurements. J Fluid Mech 311:329-371

Ross CB, Lourenco LM, Krothapalli A (1994) Particle Image Velocimetry measurements in a shock-containing supersonic flow. In: Proceedings of 32nd aerospace sciences meeting, AIAA-94-0047

Rossmann T, Mungal MG, Hanson RK (2002) Evolution and growth of large scale structures in high compressibility mixing layers. J Turbul 3:N9

Saddington AJ, Lawson NJ, Knowles K (2004) An experimental and numerical investigation of underexpanded turbulent jets. Aeronaut J 108:145-151

Saiyed NH, Bridges JE, Mikkelson K (2000) Acoustics and thrust of separate flow exhaust nozzles with mixing devices for high bypass ratio engines. In: 8th AIAA/CEAS aeroacoustics conference, AIAA-2000-1961

Sarkar S, Lakshmanan B (1991) Application of Reynolds stress turbulence model to the compressible mixing layer. AIAA J 29:743-749

Sarkar S, Erlebacher G, Hussaini MY, Kreiss HO (1991) The analysis and modelling of dilatational terms in compressible turbulence. $\mathrm{J}$ Fluid Mech 22:473-493

Slessor MD, Chang N, Dimotakis PE (2000) Turbulent shear-layer mixing: growth-rate compressibility scaling. J Fluid Mech 414:35-45

Thurow B, Samimy M, Lempert W (2003) Compressibility effects in turbulent structures of axisymmetric mixing layers. Phys Fluids $16: 1755-1765$
Thurow BS, Jiang N, Kim J-H, Lempert W, Samimy M (2008) Issues with measurements of the convective velocity of large scale structures in the compressible shear layer of a free jet. Phys Fluids 20:066101

Tinney CE, Glauser MN, Ukeiley LS (2008) Low-dimensional characteristics for a transonic jet: part 1-Proper Orthogonal Decomposition. J Fluid Mech 612:107-141

Trumper MT (2006) A study of nozzle exit boundary layers in high speed jet flows. Ph.D. Thesis, Loughborough University

Urban WD, Mungal MG (2001) Planar velocity measurements in compressible mixing layers. J Fluid Mech 431:189-222

Vreman AW, Sandham ND, Luo KH (1996) Compressible mixing layer growth rate and turbulence characteristics. J Fluid Mech $320: 235-258$

Wernet MP (2007) Temporally resolved PIV for space-time correlations in both cold and hot jet flows. Meas Sci Technol 18:1387-1403

Witze PD (1974) Centreline velocity decay of compressible free jets. AIAA J 1:417-418

Zaman KBMQ (1998) Asymptotic spreading rate of initially incompressible jets-experiment and analysis. Phys Fluids 10:2652-2660

Zeman O (1990) Dilatational dissipation: the concept and application in modelling compressible mixing layers. Phys Fluids A 2:178-188

Zhou Q, He F, Shen MY (2012) Direct numerical simulation of a spatially developing compressible mixing layer: flow structures and mean flow properties. J Fluid Mech 711:437-468 